Florida International University FIU Digital Commons

\title{
The Effects of Post-Recall Feedback: Examining Witness Recall Quantity, Accuracy, and Confidence
}

Dana Elizabeth Hirn Mueller

Florida International University, danahirn@gmail.com

DOI: $10.25148 /$ etd.FIDC000132

Follow this and additional works at: https://digitalcommons.fiu.edu/etd

Part of the Cognitive Psychology Commons, Criminology and Criminal Justice Commons, Other Psychology Commons, and the Social Psychology Commons

\section{Recommended Citation}

Hirn Mueller, Dana Elizabeth, "The Effects of Post-Recall Feedback: Examining Witness Recall Quantity, Accuracy, and Confidence" (2015). FIU Electronic Theses and Dissertations. 2169.

https://digitalcommons.fiu.edu/etd/2169

This work is brought to you for free and open access by the University Graduate School at FIU Digital Commons. It has been accepted for inclusion in FIU Electronic Theses and Dissertations by an authorized administrator of FIU Digital Commons. For more information, please contact dcc@fiu.edu. 


\section{FLORIDA INTERNATIONAL UNIVERSITY \\ Miami, Florida}

\section{THE EFFECTS OF POST-RECALL FEEDBACK: EXAMINING WITNESS RECALL QUANTITY, ACCURACY, AND CONFIDENCE}

A dissertation submitted in partial fulfillment of the

requirements for the degree of

DOCTOR OF PHILOSOPHY

in

PSYCHOLOGY

by

Dana Hirn Mueller 
To: Dean Michael R. Heithaus

College of Arts and Sciences

This dissertation, written by Dana Hirn Mueller, and entitled The Effects of Post-Recall Feedback: Examining Witness Recall Quantity, Accuracy, and Confidence, having been approved in respect to style and intellectual content, is referred to you for judgment.

We have read this dissertation and recommend that it be approved.

Jamie Flexon

Jacqueline Evans

Lindsay Malloy

Nadja Schreiber Compo, Major Professor

Date of Defense: June 18, 2015

The dissertation of Dana Hirn Mueller is approved.

\begin{tabular}{r}
\hline $\begin{array}{r}\text { Dean Michael R. Heithaus } \\
\text { College of Arts and Sciences }\end{array}$ \\
\hline Dean Lakshmi N. Reddi \\
University Graduate School
\end{tabular}

Florida International University, 2015 
(C) Copyright 2015 by Dana Hirn Mueller

All rights reserved 


\section{DEDICATION}

I dedicate the current work to my husband, Christopher Mueller, and to my

parents, David and Pamela Hirn. Only through your unwavering love, support, and patience was this work able to be completed. 


\section{ACKNOWLEDGMENTS}

I would like to sincerely thank the members of my dissertation committee. To my Major Professor, Dr. Nadja Schreiber Compo, thank you for your time, patience, and guidance through the development and execution of this research. To my committee members, Dr. Lindsay Malloy, Dr. Jacqueline Evans, and Dr. Jamie Flexon, thank you for your continued support and helpful feedback throughout the course of the current project.

To my research assistants, Vesna Babarogic, Joshua Estrada, Christopher Garcia, Jasmin Garcia, Jessica Gonzalez, Jacqueline Moats, Katherine Padron, Michael Powell, Alexander Valdes, and Claudia Vega, I am truly grateful for all the time and effort you devoted to this challenging research. I know it was not always easy, but you did a wonderful job and this study could not have been completed without you.

I am also incredibly grateful for the laughs, love, and support I received from my fellow graduate students, Andrea Arndorfer, Daniella Villalba, Jenna Cervantes, and Jillian Rivard. Through the highs and the lows you were there, and I will never know how I got so lucky to have found you.

Lastly, I would like to acknowledge the financial support throughout the creation of this manuscript provided through the Florida International University Graduate School Dissertation Year Fellowship. 


\author{
ABSTRACT OF THE DISSERTATION \\ THE EFFECTS OF POST-RECALL FEEDBACK: EXAMINING \\ WITNESS RECALL QUANTITY, ACCURACY, AND CONFIDENCE \\ by
}

Dana Hirn Mueller

Florida International University, 2015

Miami, Florida

\title{
Professor Nadja Schreiber Compo, Major Professor
}

Most eyewitness identification protocols recommend withholding feedback after an identification has been made, at least until a measure of confidence can be gathered. Although much research has examined the impact of post-identification feedback on subsequent witness behavior and confidence, research addressing the importance of postrecall feedback remains largely incomplete. The current study examined the effects of post-recall feedback and question type on subsequent witness recall, confidence, and reports of view of the crime. In line with previous eyewitness identification research, it was predicted that participants receiving confirming post-recall feedback would be more confident in their prior recall compared to participants receiving neutral, no, or disconfirming feedback. One hundred and fifty-eight participants viewed a mock crime video of a robbery followed by an interview which included both open-ended and cued questions. Participants were then given either confirming, neutral, no, or disconfirming feedback and asked about their confidence and the clarity of their view of the perpetrator. Under the pretense that the recording equipment failed, participants were interviewed again using the same question format. The second interview was followed by a series of 
suggestive questions. After the second interview, participants were again asked about their confidence and self-reported quality of view of the perpetrator. Participant interviews were transcribed and scored for quantity, accuracy, and consistency by two blind, independent coders. Analyses revealed that feedback had a systematic impact on confidence such that participants who received confirming feedback were more confident in the overall accuracy of their prior memory accounts than those who received neutral, no, or disconfirming feedback and participants who received neutral or no feedback were more confident in the overall accuracy of their prior memory accounts compared to those in the disconfirming feedback condition. In line with previous eyewitness identification research, there was no significant relationship between recall accuracy and reported confidence. Results from the current study can be used to inform real-world investigative interviewers by highlighting the consequences of offering post-recall feedback. Specifically, feedback can impact witness confidence irrespective of actual recall accuracy. 


\section{TABLE OF CONTENTS}

CHAPTER

PAGE

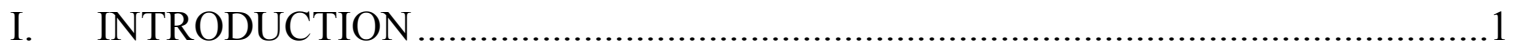

Post-Identification Feedback and Confidence: Theoretical Perspectives.................3

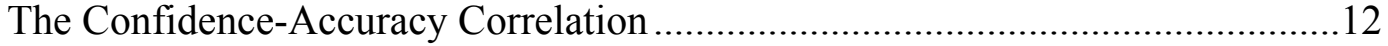

Feedback and Investigative Interviewing .................................................. 13

Rapport Building and Witness Recall............................................................ 15

Investigative Interview Question Format.......................................................19

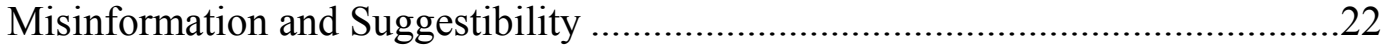

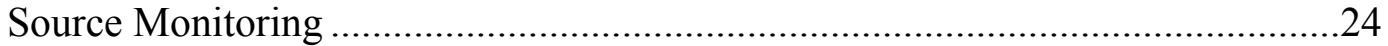

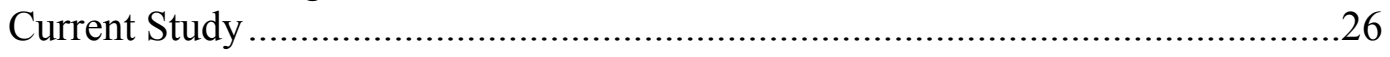

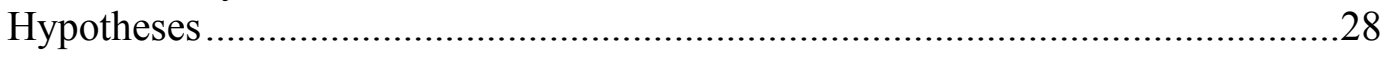

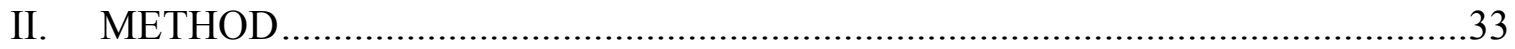

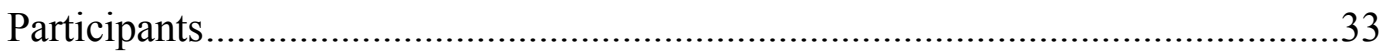

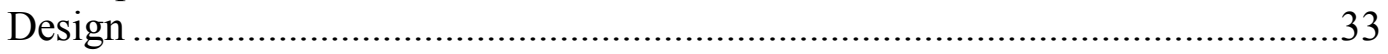

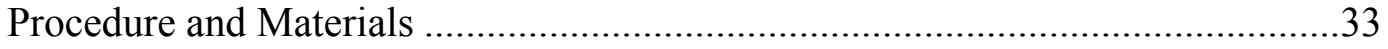

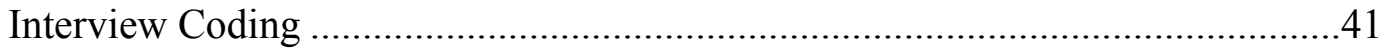

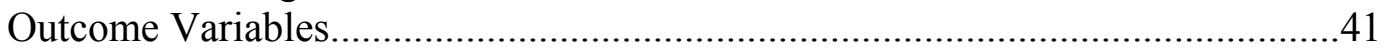

III. RESULTS ..............................................................................................4

Impact of Post-Recall Feedback on Confidence and Reports of View.................47

Impact of Question Type and Post-Recall Feedback on Witness Recall ...............52

Impact of Feedback on Consistency and Uncertain Information.........................54

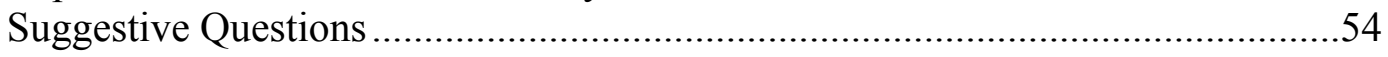

Relationship Between Confidence and Accuracy ….........................................55

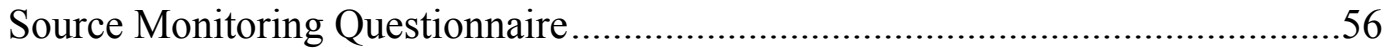

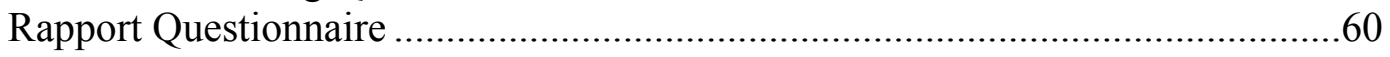

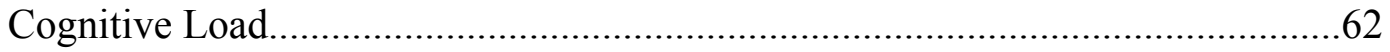

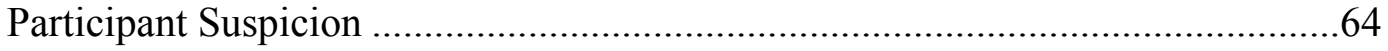

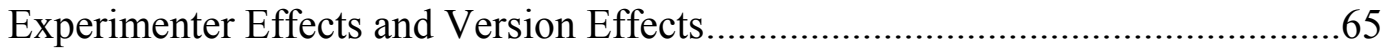

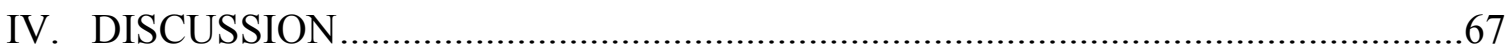

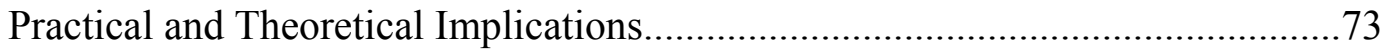

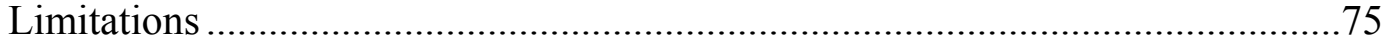

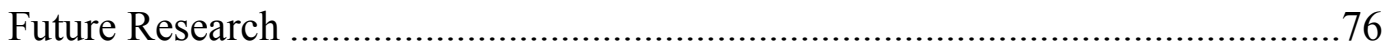

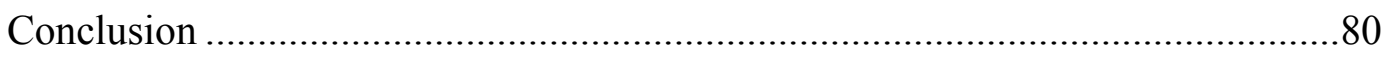

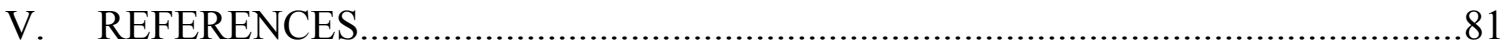

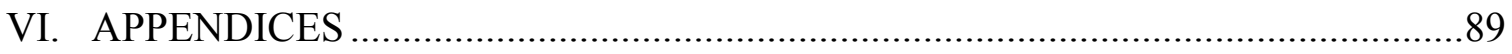

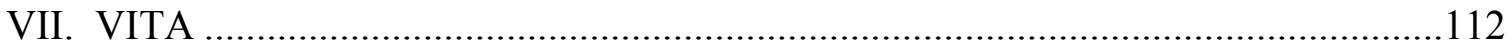




\section{LIST OF TABLES}

CHAPTER

PAGE

1. First assessment of mean reports of view of the perpetrator, reported confidence, reported ease of recall, and perceived accuracy of recall

2. Second assessment of mean reports of view of the perpetrator, reported confidence, reported ease of recall, and perceived accuracy of recall

3. Total number of units and mean percentages participants' responses in Interview 2 by feedback and question type

4. Mean number of correct acquiescences, correct rejections, incorrect acquiescences, and incorrect rejections

5. Mean number of correct, incorrect, and don't know responses of source monitoring written recall

6. Mean confidence ratings for open-ended source monitoring questions .58

7. Source monitoring accuracy, inaccuracy, and don't know response rates .59

8. Confidence ratings in source identification accuracy .60

9. Rapport interaction ratings of interviewer by feedback condition.

10. Mean ratings for measures of perceived cognitive load .64 


\section{INTRODUCTION}

Imagine that you are on your way home from work and decide to stop at an ATM to complete a transaction. While you are standing in line, a man emerges from behind a corner, pulls out a gun, and demands money from a woman in front of you. After threatening your safety as well as the safety of others in line, the robber grabs money from the woman in front of you and flees. Police are summoned and arrive on location. While still trying to regain your composure from this disturbing situation, a police officer begins to interview you. After you have given your statement, the officer shakes his head and responds, "Some of the information you have given me doesn't match the other evidence we have." Given his response, how likely might you be to change the information and level of detail you offer in a subsequent interview either at the station and/or in court? How will his feedback affect your confidence in the information you recalled? Conversely, imagine that the officer told you that the information you gave matches other information he has. How might that confirming feedback influence your subsequent recall and confidence?

Thousands of law enforcement professionals conduct investigative interviews with witnesses of crimes each day. As these interviews often play a central role in criminal investigations (Kebbell \& Milne, 1998), it is critical that they are conducted using methods which will not only gather accurate information at the time of the interview, but preserve witness memory for subsequent interviews and statements made at trial. As a consequence of the increasing number of exonerations decided on the basis of fallacious information given by witnesses, much justified attention has been paid to system variables (i.e., features of the investigative process under the control of the justice 
system) in general and the procedures surrounding lineup identifications in particular (Wells, 1978; Wells, Memon, \& Penrod, 2006; Wells, Small, Penrod, Malpass, Fulero, \& Brimacombe, 1998). Erroneous eyewitness memory during lineups has been listed as a contributing factor in approximately $75 \%$ of DNA exoneration cases (Innocence Project, n.d.; Scheck, Neufeld, \& Dwyer, 2000). Given these miscarriages of justice, legal psychology researchers have put particular effort toward addressing ways to increase the quantity and quality of information gathered from witnesses with the overarching goal of ensuring that the person who committed the crime(s) is convicted and that anyone factually innocent of the crime(s) is not convicted.

One system variable which has received considerable research attention in the context of eyewitness identifications is post-identification feedback provided by the investigator after a witness has picked a target from a lineup (Wells \& Bradfield, 1998; 1999). Post-identification feedback is defined as any information about an identification choice given to witnesses after they have identified an individual from a lineup (Neuschatz et al., 2007). For example, saying to a witness after s/he has chosen a member of a lineup: "Great job! We were hoping you'd pick him!"

Numerous studies have demonstrated that post-identification feedback can influence subsequent witness confidence as well as other self-reported measures of view of the crime including ease of making an identification and the quality of view the witness had of the perpetrator (Douglass \& Steblay, 2006; Steblay, Wells, \& Douglass, 2014). Given the importance of witness statements in criminal investigations and at trial, especially when a witness is confident (Bradfield \& Wells, 2000; Brewer \& Burke, 2002; Wells, Ferguson, \& Lindsay, 1981), it is surprising that similar attention has not been 
paid to examining the possible impact(s) of post-recall feedback. In the context of the

current study, post-recall feedback is defined as any feedback provided by the interviewer to the witness after the witness has recalled a critical event. The gaps in post-recall feedback research are critical given that virtually any witness making an identification is likely to have also been interviewed by investigators. Several obvious deficits exist within the investigative interviewing literature as the impact of post-recall feedback on subsequent witness recall, confidence, and reports of the quality of view of a critical incident is largely unexplored. One important starting point for addressing these gaps in research is to consult the wide body of literature which explores and outlines the relationship between feedback given after a lineup choice and the subsequent confidence in that choice.

\section{Post-Identification Feedback and Confidence: Theoretical Perspectives}

Research examining the impact of post-identification feedback demonstrates that confirming post-identification feedback increases eyewitness confidence, the level of attention reportedly paid to the critical event, the reported amount of time the perpetrator was visible to the witness, and the reported ease of an identification (Douglass \& Steblay, 2006; Steblay et al., 2014). One potential explanation for the substantial impact of postidentification feedback is hindsight bias or the "knew-it-all-along" phenomenon (Fischhoff, 1977). Hindsight bias is the tendency to find the outcome of an event more predictable after the outcome has already been established. Thus, offering confirming feedback to a witness who has just identified a suspect may lead the witness to believe that, because the outcome is now known and confirmed, it was easier to identify the suspect than it really was. 
Self-perception framework. A second theoretical way in which the effects of post-identification feedback can be interpreted is through Bem's $(1967 ; 1972)$ selfperception theory. Self-perception theory posits that when the internal cues to interpreting our own behavior and/or motives are ambiguous, we use external cues such as our actual behavior to help interpret those cues (Bem, 1967; 1972). For example, if witnesses are unsure of their memory of a perpetrator but then choose a member of a lineup, witnesses may infer that they must have a good memory of the perpetrator because they picked a member of a lineup. Self-perception theory has been supported, for example, by research suggesting that manipulating facial expression can influence mood (Laird, 1974; Strack, Martin, \& Stepper, 1988). Here, participants were asked to either hold a pen in their mouth in such a way that it forced those participants to smile or maintain a facial expression that inhibits smiling. All participants were then asked to watch and rate various videos (e.g., cartoons). Participants who were forced to smile subsequently rated cartoons as being funnier than participants who were not able to smile (Laird, 1974; Strack et al., 1988).

In the context of post-recall feedback, the self-perception framework would predict that witnesses who report information about a critical event will use their own behavioral cues (i.e., recalling information about a crime) to glean a feeling of confidence about that recall. In other words, witnesses may recall a target event and use that behavior to conclude that, because they have recalled information about the critical event, they must have a strong memory of that event. However, despite the insight the selfperception perspective offers, a direct theoretical framework which has been used to 
explain why post-identification feedback can influence confidence and reports of quality of view is the cue-accessibility framework (Wells \& Bradfield, 1998).

Cue-accessibility framework. The cue-accessibility framework states that witnesses do not form an impression of an incident while the incident is occurring, which is a key difference between self-perception theory and the cue-accessibility framework. Instead, witnesses form an impression of their confidence after a choice has been made (e.g., selection of a lineup member) using various cues (e.g., a lineup administrator saying, "Great! You identified the suspect!") (Bradfield, Wells, \& Olson, 2002; Charman, Carlucci, Vallano, \& Hyman Gregory, 2010; Hastie \& Park, 1986; Steblay et al., 2014).

The cue-accessibility framework was developed and tested by Wells and Bradfield (1998) who asked participants to watch grainy security camera footage of a perpetrator committing a real crime. Participants were then shown a target-absent lineup. After an identification was made, participants were either given confirming, disconfirming, or no feedback. Participants given confirming feedback were told, “"Good. You identified the actual suspect in the case,"' participants given disconfirming feedback were told, “'Oh, you identified number . The actual suspect is number _,"'and participants in the control condition were not given any feedback (Wells \& Bradfield, 1998, p. 363). Results showed that participants given confirming feedback not only reported being more certain of the choice they had made, but in their confidence and reports of view of the perpetrator compared to participants given no or disconfirming feedback. Disconfirming feedback was shown to have a deleterious effect on confidence, but not to the same extent that confirming feedback had on elevating witness confidence. 
Similar studies of post-identification feedback have expanded the original framework and findings by using elderly participants and comparing the impact of confirming post-identification feedback to that of the frequently used college-age sample (Neuschatz et al., 2005). Consistent with the findings of previous research, age did not have an impact on confidence of participants who were given confirming postidentification feedback (Neuschatz et al., 2005). That is, both elderly and college-aged participants expressed similarly high confidence after being given confirming postidentification feedback compared to both elderly and college-aged participants who were given no post-identification feedback. Similar results were found after a one week delay in a second study (Neuschatz et al., 2005), in contrast to other research demonstrating that elderly persons are more vulnerable to suggestion compared to young adults (Karpel, Hoyer, \& Toglia, 2001). Neuschatz and colleagues aruged that these findings also support the cue-accessibility framework as participants who were given confirming feedback could deduce that they must have had a clear view of the perpetrator and were confident in their identification after they received confirming post-identification feedback.

The cue-accessibility framework further postulates that witnesses are unable to use the actual recall of their identification experiences independently of subsequent feedback, and as such, are unable to make confidence assessments "online" (Wells \& Bradfield, 1998, pp. 362). Thus, witnesses are typically unaware of the effect that postidentification feedback has on confidence, as evidenced by the finding that those who were unaware of its impact were influenced just as much as participant witnesses who admitted that feedback may have impacted their confidence and ease of identification (Wells \& Bradfield, 1998). People may display a lack of awareness because they are 
often poor at introspection and are unaware of their underlying cognitive processes (Nisbett \& Wilson, 1977; Wilson, 2002).

There are, however, some limitations to the cue-accessibility framework. First, it does not account for the possibility of external cues not being incorporated into confidence assessment (Charman et al., 2010). For example, an external cue (e.g., "You identified the suspect!") may not be considered credible by the witness (e.g., if the witness is suspicious of the motives of the investigator for offering confirming feedback) and would thus not be included in the confidence assessment of the witness. Indeed, ulterior motives of the lineup administrator have been found to mitigate the inflating effects of confirming post-identification feedback (Neuschatz et al., 2007). Specifically, Neuschatz and colleagues (2007) asked participants to view a lineup and then gave half of participants confirming feedback while the other half received no feedback. Among the half of participants who received confirming feedback, researchers then created suspicion as to the motives of the lineup administrator for offering confirming feedback. Results showed that suspicious participants did not experience the same confidence inflation as to participants who were not suspicious. Second, the cue-accessibility framework does not provide an explanation as to why certain post-identification feedback instructions, such as asking the witness to consider the motives of the administrator, are effective in eliminating the effects of post-identification feedback (Charman et al., 2010).

Selective cue integration framework. Building upon and addressing some of the limitations of the cue-accessibility framework (e.g., credibility evaluation of an external cue), the selective cue integration framework (SCIF) was developed to explain how witnesses may assess their own confidence after choosing a member in a lineup 
(Charman et al., 2010). The SCIF proposes a three-stage process (Appendix A). First, when witnesses try to assess their confidence about a decision, they will first attempt to assess internal cues (i.e., how confident they feel about the lineup choice). During the first stage (assessment), if internal cues are strong (e.g., witnesses believe they have a good memory of the perpetrator and thus picked the correct person in the lineup), witnesses will make a confidence judgment using these internal cues. However, the weaker the internal cues, the more inclined witnesses will be to search for external cues to determine their own confidence, which leads witnesses to the second stage.

In the second stage (search), witnesses seek and either incorporate or disregard external cues depending on the extent to which those cues support preexisting beliefs. Specifically, if the external cue is confirming, witnesses will accept that cue, but if the external cue is disconfirming, witnesses will be less likely to accept that cue. Acceptance of confirming cues can be explained by our desire to see ourselves as competent and accurate in our decisions (Blanton, Pelham, DeHart, \& Carvallo, 2001). We also tend to be motivated to readily accept confirming information while closely examining disconfirming information in an attempt to disregard that information (Lord, Ross, \& Lepper, 1979). Thus, if the external cue is confirming, witnesses will incorporate that cue and move on to the third stage (evaluation). However, if the cue is disconfirming, witnesses will not move on to the evaluation stage. If witnesses do not move on to the evaluation stage on the basis of one cue, they will move on to looking for other external cues to assess their confidence.

Upon entering the third stage (evaluation), witnesses evaluate the credibility of the external cue and if there is no information available which undermines the credibility 
of the cue, that cue will be used by witnesses to assess their confidence. In other words, if witnesses do not see the source of the cue as unreliable, that cue will be incorporated into their confidence assessment. For example, if witnesses receive confirming feedback from a police officer involved in the case and there is no evidence witnesses have which would undermine the credibility of that investigator and/or the feedback s/he is offering, witnesses will generally consider the investigator to be credible. As a result, witnesses will likely incorporate the information from that source into their confidence judgment. It is important to note that the acceptance of the cue does not hinge on witnesses searching for information which bolsters the credibility of the cue. Rather, only if there is no information to indicate unreliability of the cue, will the cue be accepted. The prediction for the acceptance of the cue is based on our tendency to judge a cue by the credibility of the source rather than the content of the cue (e.g., Petty, Cacioppo, \& Goldman, 1981). If the feedback is perceived to be unreliable, witnesses will likely look for other information to determine confidence in their decision.

Application of the SCIF to post-recall feedback. Taken together, the SCIF can help provide a theoretical framework to explain how post-identification feedback can affect confidence judgments. Applied to the context of post-recall feedback, the SCIF would predict that when witnesses are asked about their confidence and reports of view after being provided with feedback about a statement, they will begin by assessing their internal cues. If the internal cues are strong, they will make a confidence judgment using those internal cues. However, if internal cues are weak, they will begin to search for external cues, such as feedback from the interviewer. If the incoming cue (post-recall feedback) is confirming, witnesses will accept that cue and move on to the third stage 
(evaluation). However, if the cue is disconfirming, witnesses will search for other cues to form a confidence judgment.

If witnesses have moved on to the third stage, witnesses will evaluate the credibility of the external cue. If there is no information available which undermines the cue, then witnesses will incorporate the post-recall feedback into their confidence assessment. However, if there is information available that discredits the cue, that cue will not be incorporated into their confidence assessment. In the case of post-recall feedback, a piece of potentially discrediting information could be the perception that the investigator has no knowledge of the crime. Thus, the investigator offering post-recall feedback could be seen as uninformed and unqualified to offer accurate post-recall feedback.

Taken together, providing witnesses with post-identification and post-recall feedback may be problematic for three chief reasons. First, providing confirming feedback to witnesses may inflate their confidence, regardless of the accuracy of the information provided by the witness. Similarly, giving witnesses disconfirming feedback after their statements may deflate their confidence irrespective of statement veracity. Although the SCIF suggests that witnesses are likely to disregard external cues that are not confirming, disconfirming feedback after a lineup identification has been shown to have a deleterious impact on witness confidence (Douglas \& Steblay, 2006; Steblay et al., 2014; Wells \& Bradfield, 1998), even if it is not as impactful as the effect of confirming feedback on confidence (Douglas \& Steblay, 2006). In other words, although witness confidence is expected to increase more as a result of confirming feedback than witness confidence decreases as a result of disconfirming feedback, (Douglas \& Steblay, 2006; 
Steblay et al., 2014; Wells \& Bradfield, 1998), both are expected to have an effect (to varying degrees).

Although the SCIF contends that disconfirming feedback will not have a deleterious impact on confidence, Charman et al. (2010) is the only study to date supporting that prediction. Further, the SCIF has only been examined in the context of feedback for an identification, which is a single piece of information given by the witness. However, during an investigative interview, witnesses are almost certainly offering multiple pieces of information potentially increasing the likelihood of feedback and thus error compared to an identification. As a result, confidence may be increasingly malleable. Thus, both confirming and disconfirming feedback may be more impactful to confidence in the accuracy of a recall opportunity compared to confidence in the accuracy of an identification.

Further, providing disconfirming feedback may leave witnesses particularly vulnerable to the introduction of subsequent suggestive information - an interviewing pattern unique to and relevant in witness interviewing contexts compared to identifications. Examining the impact of interviewing techniques is critical given that poor patterns of interviewing are sometimes found in real-world investigative interviews (Schreiber Compo, Hyman Gregory, \& Fisher, 2012). That is, if witnesses who are given disconfirming feedback believe that an investigator has information about a case that exceeds their recall and that the investigator is a credible source, witnesses may be more likely to acquiesce to subsequent suggestions made by the investigator compared to witnesses offered confirming or no feedback. In addition to theoretical foundations for the impact of post-identification feedback, it is critical to examine the relationship 
between the confidence of witnesses in their selection of a lineup and the actual accuracy of that identification.

\section{The Confidence-Accuracy Correlation}

The confidence-accuracy correlation can be defined as the relationship between the mean confidence witnesses have in the accuracy of their choice during a lineup identification task (predicted performance) and the accuracy of their identification (actual performance) (Wells et al., 1998). Researchers have conducted a multitude of studies failing to show a significant, reliable relationship between confidence and accuracy which may indicate that confidence is not diagnostic of accuracy (Wells et al., 1998). In other words, the confidence of witnesses in their identifications has not reliably been shown to correlate with the accuracy of their identifications. Although many researchers have not demonstrated a reliable, significant relationship between confidence and accuracy (Wells \& Murray, 1984), there may be some evidence of a confidence-accuracy correlation.

For example, using a sample of 35 studies, Bothwell, Deffenbacher, and Brigham (1987) found a significant moderate relationship between the confidence witnesses had in their identification and the actual accuracy of their lineup choice. Results revealed a moderate correlation between confidence and accuracy $(r=.25)$. Further, the most recent meta-analysis examining studies assessing the confidence-accuracy correlation found a moderate relationship between confidence and accuracy (Sporer, Penrod, Read, \& Cutler, 1995). Specifically, Sporer and colleagues used a sample of 30 studies and found a significant moderate correlation between confidence and accuracy $(r=.29)$. 
There may be several explanations for varying and/or moderated research findings on the relationship between confidence and accuracy in lineup research including varied witness viewing conditions (Lindsay, Read, \& Sharma, 1998) and the way in which confidence and accuracy are calculated (Brewer \& Wells, 2006; Weber \& Brewer, 2003) and assessed (e.g., verbally versus numerically). However, given that the current study is one of the first to examine post-recall feedback and the relationship between postfeedback recall and accuracy, potential moderators between confidence and accuracy were not explored. Rather, the current study focused primarily on the impact of feedback on accuracy and quantity of information elicited during recall.

\section{Feedback and Investigative Interviewing}

Despite the potential impact of post-recall feedback, few studies to date have examined the effects of feedback in the investigative interviewing arena. In two such studies, participants watched a nonviolent video clip and were interviewed using a series of open-ended and cued questions. Participants were then given either neutral feedback ("Thank you for answering these questions. To ensure that we have recorded your answers correctly, we'll run through the questions once more.") or negative feedback ("From my records here I see that others we've asked about this have done better than you. I'd like you to try again, to see if you can do better.”) (McMurtrie, Baxter, Obonsawin, \& Hunter, 2012a; 2012b, pp. 960; 593). McMurtrie and colleagues (2012a) found that participants were more likely to change their original responses on a subsequent recall opportunity when given disconfirming feedback compared to participants who were given neutral feedback. Further, McMurtrie et al. (2012b) postulated that participants receiving disconfirming feedback may have had heightened 
anxiety which may have led to a change in a subsequent recall opportunity as a function of disconfirming feedback.

Despite the development of these studies, there were several areas that were left unexplored. First, neither study examined the possible effects of confirming or no feedback, which may help disentangle the respective effects of positive versus negative approaches to providing witnesses with feedback. The authors also did not examine the effects of feedback on witness resistance or vulnerability to suggestion. Further, source monitoring was not measured to determine a possible impact of feedback on witnesses' subsequent ability to differentiate between memory sources. Researchers also did not ask participants for reports of quality of view (e.g., how clearly the witness saw the perpetrator) to parallel findings on post-identification feedback and to assess any possible effects of feedback on retrospective evaluations of witnessing conditions. Finally, these studies did not examine whether question format played a role in the effect of feedback on subsequent recall. That is, if a possible effect of post-recall feedback on subsequent recall depends on recall format (e.g., open-ended vs. cued).

Post-recall feedback has also been examined using the Deese-RoedigerMcDermott-Read-Solso (DRMRS) paradigm coupled with the implementation of confirming, disconfirming, or no feedback (Pirmoradi \& McKelvie, 2014). To examine the effect of post-recall feedback on witness confidence and post-feedback recall, participants were first asked to memorize three word lists. Participants were then asked to write their confidence in the accuracy of each word recalled and then give an overall confidence rating for each list. Participants were then given either confirming, disconfirming, or no feedback on the accuracy of their previous recall. After feedback, 
participants were asked about their confidence in the overall recall accuracy of all three word lists. Lastly, participants were asked to remember an additional six word lists. Results revealed that participants who received disconfirming feedback were significantly less confident in the accuracy of their previously recalled word lists than participants who received confirming or no feedback. Data further revealed that memory performance for subsequent word lists did not differ as a function of feedback.

One primary difference between the Pirmoradi and McKelvie (2014) study and typical post-identification feedback paradigms is that both specific and general measures of confidence were taken before feedback was given rather than after. Thinking about the accuracy of one's response(s) before receiving feedback has been shown to protect against inflated post-feedback confidence (Wells \& Bradfield, 1999). Known as the feedback prophylactic effect, it may account for the lack of difference typically found between the reported confidence of participants given confirming feedback compared to participants given no or disconfirming feedback. Thus, the current study will further address remaining gaps in the literature by exploring the effects of post-recall feedback on confidence without asking participants to consider their pre-feedback confidence.

\section{Rapport Building and Witness Recall}

A potential way to explain how post-recall feedback may affect witnesses' subsequent recall is via the effect(s) it may have on the relationship between interviewer and witness. As such, providing witnesses with confirming feedback after a recall attempt could be considered an instance of rapport building. While there is no consistently agreed-upon definition of rapport (Hall, Roter, Blanch, \& Frankel, 2009; Vallano \& Schreiber Compo, 2015), rapport in an investigative interview setting may best be 
defined as a "harmonious, sympathetic connection to another" (Newberry \& Stubbs, 1990, p. 14).

Some research supports the use of rapport building, demonstrating that witnesses who are exposed to rapport building tend to recall more accurate information compared to those not given rapport (Collins, Lincoln, \& Frank, 2002). Rapport has also been found to decrease inaccuracy (Vallano \& Schreiber Compo, 2011) and to increase the recall of accurate information if built before misinformation has been introduced (Kieckhaefer, Schreiber Compo, \& Vallano, 2014). Vallano and Schreiber Compo (2011) have also found that witnesses who were exposed to rapport gave a higher rate of accurate information and were more resistant to the introduction of misinformation than participants who received no rapport.

Building rapport is recommended in several best practice guidelines including the Cognitive Interview (CI) (Fisher \& Geiselman, 1992), the National Institute of Justice Eyewitness Evidence Guide for Law Enforcement (Technical Working Group for Eyewitness Evidence, 1999; 2003), and the NICHD Investigative Interviewing Protocol (Orbach, Hershkowitz, Lamb, Sternberg, Esplin, \& Horowitz, 2000). Rapport building is also recommended as part of the PEACE model for investigative interviewing (Home Office, 2002) as well as the PRICE model recommended for use by Scottish law enforcement professionals (Memon, 2009). Although the use of rapport is widely recommended, the ways in which rapport can and should be established vary somewhat between recommendations.

Feedback and rapport. Although guidelines and researchers differ in how they define and operationalize rapport, they agree that in order to establish rapport, interviewer 
and witness must have a friendly, supportive, and respectful relationship. As such, providing feedback to witnesses could be considered an instance of rapport. It may be that in addition to building rapport with witnesses as suggested by the CI and other interviewing guidelines, rapport can be established in other ways or, at the very least, the perception of rapport may be introduced. In other words, offering a witness confirming feedback (e.g., "Great, a lot of the information you gave me matches what I already had.”) or even neutral feedback (e.g., "Thank you for coming in today and giving me your statement.") could be interpreted as rapport by a witness. Conversely, offering disconfirming feedback (e.g., "Some of the information you gave does not match the information I have.") may be considered an instance of negative rapport.

It has been suggested that one way positive rapport can affect witness recall is via a reduction of cognitive load (Kieckhaefer et al., 2014). Research on cognitive load borrows from the well-established finding that people have finite cognitive resources when acting as processors and generators of information (Baddeley, 1986; Kahneman, 1970; 1973). Arguably, when attempting to reproduce an accurate and plentiful recollection of a crime during an interview, cognitive demands of witnesses are increased. Witnesses may be engaging in monitoring their behavior as well as the behavior of the interviewer for feedback and engaging in the demanding process of generating retrieval cues, all of which have the potential to increase cognitive load (Kieckhaefer et al., 2014). As such, an interviewer who builds rapport with witnesses may help to reduce or eliminate cognitive load. Building rapport could also help reduce or eliminate excessive pressure that witnesses may feel to be helpful, which may reduce witnesses' monitoring of their behavior as well as the behavior of the interviewer. In light 
of the emerging research on the effects of rapport on witness recall, it is important to explore whether offering confirming feedback to witnesses can facilitate subsequent recall by reducing cognitive load. It will also be important to assess whether offering disconfirming feedback inhibits recall by increasing cognitive load. To determine the potential effects of feedback on cognitive load, a measure of perceived cognitive load was included in the current study.

Offering disconfirming feedback, in turn, may increase cognitive load which could be detrimental to recall. Specifically, it may increase cognitive load by prompting witnesses to monitor the interviewer more closely for additional cues to their perceived accuracy. Witnesses may also demonstrate increases in cognitive load after disconfirming feedback by testing additional ways to be helpful and produce information. Witnesses may then devote additional cognitive resources to monitor the interviewer for any feedback which may cue them to the "correct" response to give.

Further, providing witnesses with confirming post-recall feedback may have the potential to be beneficial if the information gathered from witnesses is highly accurate. If witnesses recall a significant number of accurate pieces of information during an interview after which confirming feedback is given, those same pieces of information may have an increased chance of being recalled during a subsequent interview. Thus, the more accurate the initial witness statement, the more beneficial confirming feedback may be on subsequent recall. However, confirming feedback may also increase the likelihood with which a piece of inaccurate information will be recalled again. As such, it is particularly critical for investigators using confirming feedback to maximize the opportunity to obtain accurate information initially while simultaneously reducing the 
likelihood of gathering inaccurate information. One of the most important ways to ensure the elicitation of accurate information in conjunction with post-recall feedback would be the use of best practice investigative interviewing techniques and the avoidance of problematic techniques.

\section{Investigative Interview Question Format}

The current study examined the effects of post-recall feedback on information recalled using different recall formats. A myriad of studies have demonstrated the effects of question format on recall quantity and accuracy (e.g., Hammond, Wagstaff, \& Cole, 2006; Henry \& Gudjonsson, 1999; Koriat \& Goldsmith, 1996; Memon \& Vartoukian, 1996), confirming that open-ended question formats consistently yield a higher quantity of accurate witness information than closed or suggestive question formats. As such, a thorough examination of the post-recall feedback effect should account for different question formats documented in real-world interviewing (Fisher, Geiselman, \& Raymond, 1987; Schreiber Compo et al., 2012).

Open-ended questions. A considerable amount of research has allowed for evidence-based recommendations of investigative interviewing techniques (Fisher \& Geiselman, 1992; Orbach et al., 2000; Powell, Fisher, \& Wright, 2005; Technical Working Group for Eyewitness Evidence, 1999; 2003). One of the central techniques recommended across best practice guidelines is the use of open-ended questions. Openended questions can be defined as questions which allow for a free narrative or unstructured response from a witness (e.g., "Tell me everything you can remember about the person who robbed the convenience store."). 
The benefits of asking open-ended questions are threefold. First, allowing witnesses to give a free narrative allows witnesses to disclose information in the way it is represented in their memory. For example, witness A may recall information about a critical event in chronological order while witness B discloses information according to what $\mathrm{s} / \mathrm{he}$ feels is most important. Asking witness B a question about what happened chronologically (e.g., "Tell me everything that happened first. What happened after that?") may inhibit the recall of witness B. Second, asking open-ended questions may help to encourage active witness participation by allowing the witness to be vocal throughout the interview. Third, Koriat and Goldsmith (1996) suggest that giving witnesses an option to withhold an unsure response will decrease overall inaccuracy of recall. That is, if a participant is asked to recall a fact of which he or she is unsure, not forcing that participant to respond will lead to an increase in accurate responses compared to inaccurate responses. These findings were further confirmed by Evans and Fisher (2011) who found that participants who were given an option to withhold information about which they were unsure recalled more accurately overall compared to participants who were not explicitly given that option. A potential explanation for the reduction in inaccuracy is that when people are given the opportunity for a free narrative, they are better able to accurately monitor their own knowledge in conjunction with choosing their own output criterion. Thus, witnesses may choose to offer only information they believe to be correct and because they are encouraged to answer the question in an open-ended format, they are able to choose which information to offer and which information to withhold. 
In sum, open-ended questions offer a variety of benefits to witnesses and investigators and generally allow for witnesses to maximize accurate recall. However, although open-ended questions are a staple of best practice investigative interviewing, cued questions can and do serve a purpose to help elicit specific information from witnesses.

Cued questions. To gather highly detailed and specific information, the use of cued questions can be helpful in an investigative interview by gathering information not obtained via open-ended questions (Powell \& Thomson, 1996). Question format (openended vs. cued) has been studied more frequently with children than adults, but the mechanisms which allow cued questions to be helpful for children arguably also hold true for adults. As opposed to open-ended questions, cued questions are asked with the intention of eliciting a specific piece of information. Cued questions are used frequently in real-world investigative interviews (Schreiber Compo et al., 2012), forensic interviews with children, and are often conceptualized as "Wh" questions (e.g., Who, What, When, etc.) during these interviews (Miles, Powell, Gignac, \& Thomson, 2007, p. 218).

Cued questions can help witnesses recall specific pieces of information more effectively than open-ended questions as cued questions provide information contained in the question that will cue witnesses to information that they may not have been able to retrieve during a free narrative (Dent $\&$ Stephenson, 1979). In other words, cued questions can act as a retrieval cue for information that would not have been recalled by free recall alone. However, as noted by Evans and Fisher (2011), cued recall questions may be unhelpful as these questions both force witnesses to respond and do not allow witnesses to control the specificity or precision of the information being offered. Thus, 
cued questions should be used minimally, but may sometimes be able to help elicit important, specific details not mentioned by witnesses during a previous free narrative. In addition to excessively relying on cued questions, there are various problematic investigative interviewing techniques which should be assiduously avoided by interviewers.

\section{Misinformation and Suggestibility}

The factors conducive and detrimental to witness memory have been studied by legal psychology researchers for decades, due to both their theoretical and applied significance (e.g., Lindsay \& Johnson, 1989; Memon, Meissner, \& Fraser, 2010; Steblay, 1992; 1997; Wells et al., 1998). There are a variety of interviewing techniques and other investigative risk factors which can render witnesses vulnerable to falsely recalling information such as the introduction of misinformation after a critical event has occurred. The misinformation effect has typically been described as introducing incorrect information about an original event to witnesses which alters accuracy of the memory for the original event (e.g., Ayers \& Reder, 1998; Loftus \& Palmer, 1974).

Given that memory is a reconstructive process, the introduction of misinformation - particularly through the use of suggestive questions - during the process of reconstruction can substantially alter subsequent witness recall (Lindsay, 1990; Loftus, 1975; Loftus, Miller, \& Burns, 1978; Loftus \& Palmer, 1974; Loftus \& Zanni, 1975; McCloskey \& Zaragoza, 1985). Suggestive questions can be defined as questions that introduce new information into the interview and suggest to witnesses the answer that interviewers expect. For example, if a witness has not yet described the clothing of a thief and the interviewer asks, "Was the perpetrator wearing a red shirt?", that question 
introduces information (color of the shirt) that was not yet disclosed and suggests to the witness the answer the interviewer expects.

A plethora of research has documented that the introduction of misinformation via suggestive questions can alter both the witness statement about and memory for an event (Loftus, 1975; Loftus and Palmer, 1974; Loftus \& Zanni, 1975). Over time, several theoretical mechanisms for the misinformation effect have been proposed. Originally, Loftus (1975) proposed the trace overwrite hypothesis. The trace overwrite hypothesis suggests that the original memory for an event could actually be overwritten by the new (misinformation) and therefore the new memory (misinformation) would be recalled in a subsequent recall attempt. McCloskey and Zaragoza (1985) challenged the overwriting hypothesis via a cleverly designed series of experiments which suggested that participants were simply conceding to what they believed were the demand characteristics of the recall situation. That is, participants were able to perceive the responses experimenters expected and responded to meet the expectations of the experimenter.

Feedback and suggestibility. Estimating the possible effects of post-recall feedback can also be informed by the Gudjonsson Suggestibility Scale (GSS) (Gudjonsson, 1984). According to the interrogative suggestibility model as measured by the GSS, negative feedback has been suggested as being potentially impactful in affecting the likelihood of a suspect confessing during an interrogation (Gudjonsson \& Clark, 1986). To examine interrogative suggestibility, Gudjonsson and Clark (1986) constructed a model to help predict the outcome of an interrogation. One of the elements of the interrogative suggestibility model included interrogative pressure, which is described as 
any influence applied by the interrogator which may interfere with the accuracy of information given by the suspect. A primary way to apply interrogative pressure is by giving negative feedback (Baxter, Charles, Martin, \& McGroarty, 2012). Within the context of the GSS, feedback is conceptualized as a message to the interviewee from an interrogator with the primarily goal of strengthening or modifying the response of the suspect (Gudjonsson \& Clark, 1986).

Suspects may perceive negative feedback during an interrogation as being unsupportive on the part of the interviewer (Bain \& Baxter, 2000) and, as such, may result in an increase in anxiety and a reduction in self-esteem (Gudjonsson \& Clark, 1986). In an attempt to decrease anxiety, people may look to the interrogator for approval and cues which suggest whether a question has been answered satisfactorily (Gudjonsson, 1988). According to interrogative suggestibility model, the use of negative feedback may increase compliance and suggestibility (McMurtrie et al., 2012b). Applied to the witness context, the model would predict that participants who are given negative feedback would be less confident in subsequent recall opportunities and more vulnerable to the introduction of misinformation via suggestive questions.

\section{Source Monitoring}

More recently, the source monitoring framework allowed for the inclusion and explanation of both the trace overwrite hypothesis and demand characteristic work by McClosky and Zaragoza (Johnson, Hashtroudi, \& Lindsay, 1993). Specifically, the source monitoring framework provides a more encompassing explanation for the misinformation effect, where both sources, the original information and the misinformation co-exist and are chosen via attributional processes. As such, source 
monitoring can be defined as the process involved in making attributions about the source(s) of our knowledge and memory (Johnson, Bush, \& Mitchell, 1998; Johnson et al., 1993), which can be internal (i.e., something stored in our memory) or external (i.e., information given by an interviewer). According to the source monitoring framework, the misinformation effect can occur when a witness incorrectly attributes a piece of misinformation to their own memory instead of an outside source (e.g., a suggestive interviewer). The source monitoring framework has been successfully used to explain suggestibility and misinformation effects in witness recall scenarios given the nature of the to-be-remembered material and the potential for outside information (or misinformation) that may be presented (Mitchell, Johnson, \& Mather, 2003).

Because witnessing a crime can be very complex, the potential for source confusion introduced through suggestion and outside (mis)information is high (Belli \& Loftus, 1994; Mitchell \& Johnson, 2000). Given the well-researched impact of source monitoring errors on memory and recall (Johnson et al., 1993), the way(s) in which postrecall feedback can affect subsequent recall attempts and witness source monitoring abilities is important to understand. Source monitoring can be a complex process including both heuristic judgments and a systematic reflection of the source of one's knowledge (Johnson, DeLeonardis, Hashtroudi, \& Ferguson, 1995). As such, there may be a variety of ways in which source monitoring abilities may be interrupted (Johnson et al., 1993; Johnson et al., 1995). One of the ways source monitoring processes may be disrupted is that information about an event is not simply retrieved, but also combined with information from external cues present at the time of retrieval (Tulving, 1983) which may lead to errors if such cues are incorrect. Within the context of feedback during an 
investigative interview, offering disconfirming feedback to witnesses may disrupt their subsequent source monitoring decision making such that ease, vividness, and salience of recall may no longer be used as indicators of an external source of that memory. Conversely, if witnesses are given information suggesting that their recall is accurate, a lack of ease, vividness, and salience of recall may also no longer be used as indicators that a specific memory has not been externally generated.

Despite research-based recommendations, many real-world interviewers continue to use closed or suggestive questions when interviewing witnesses (Schreiber Compo et al., 2012). As feedback may manipulate the confidence of witnesses regardless of the accuracy of their recall for an event, it is particularly important to examine those question types most vulnerable to outside influence. The current study therefore included openended, cued, and suggestive questions to test for any possible interactions between postrecall feedback and question format.

\section{Current Study}

The present research is the first to address the effects of confirming, neutral, no, and disconfirming post-recall feedback and question format on subsequent witness recall accuracy, quantity, suggestibility, confidence, and self-reported ratings of quality of view. Specifically, the study had four primary goals: (1) examine the effects of confirming, neutral, no, or disconfirming post-recall feedback on subsequent eyewitness recall, confidence, and reports of view of the crime; (2) examine the effects of different types of feedback on witnesses' subsequent suggestibility to misinformation; (3) examine possible interactions between post-recall feedback and open-ended versus cued question

format on witness recall, confidence, and reports of view of a crime; (4) assess the impact 
of feedback on the accuracy of witness source monitoring. In sum, the overarching goal of the current research is to examine what type(s) of feedback and question format would be detrimental or possibly helpful in eliciting a higher quantity of accurate witness information under subsequent varying recall conditions.

Contribution to the literature. The current study addresses a variety of novel areas which previous research has not yet explored. There are seven ways in which the current research contributes to remaining gaps in the literature focusing on the impact of post-recall feedback on witness memory and confidence. First, the current study examined underlying theoretical approaches that could potentially explain the impact of post-recall feedback on witness recall and self-reported measures of view. The current research used both measures of rapport and reported cognitive load to examine the ways in which varying types of feedback could affect rapport and cognitive load, which may be linked to recall quantity and accuracy.

Second, the current study was the first to examine the impact of post-recall feedback on subsequent reports of confidence and other reports of view of a critical event. Pirmoradi and Stuart McKelvie (2014) examined post-recall feedback, but asked for measures of confidence before feedback was given. Asking participants for measures of confidence before they are given feedback has been shown to assuage the impact of confirming feedback on subsequent confidence (Wells \& Bradfield, 1999).

Third, the current research was the first to examine a possible interaction between feedback and question format. That is, to date, no research has examined how feedback interacts with witness recall in response to open-ended and cued questions. The potential interaction between question type and feedback is critical given that best practice 
research-based guidelines tend to encourage the use of open-ended questions and cued questions are often used by real-world interviewers. In sum, law enforcement investigators are likely to use both open-ended and cued questions.

Further, no research has been conducted to disentangle possible effects of neutral feedback versus no feedback. Eyewitness identification literature typically uses a "no" feedback condition as a control group without examining whether neutral feedback (i.e., feedback about the recall of a witness without commenting on accuracy) is different from no feedback. Fifth, the current study was the first to examine the potential impact of feedback on witness suggestibility. Witness suggestibility as a function of feedback is of particular concern as confident witnesses are typically seen as more credible, but confidence may be rendered undiagnostic via suggestion.

Also, the current study examined the impact of post-recall feedback on source monitoring accuracy as well as confidence in source monitoring accuracy. It was important to continue exploring the possible ways in which feedback may enhance or interrupt source monitoring processes. Lastly, the current research was the first to gather a comprehensive inventory of the impact of post-recall feedback not only on witness confidence, but on the reported length of view of the perpetrator, clarity of view of the perpetrator, ease of recall during the interviews, level of attention paid to the perpetrator, and perception of recall accuracy.

\section{Hypotheses}

There were a total of four hypotheses, each of which corresponds to the primary goals of the current study. Each hypothesis will discuss the predicted outcomes for the current study as well as the literature which supports each prediction. 
Hypothesis one. The first hypothesis predicted that feedback would affect quantity and accuracy of witness information provided at a subsequent recall attempt such that participants receiving confirming feedback would report more accurately and more extensively than participants who received no, neutral, or disconfirming feedback and participants receiving no or neutral feedback would report more accurately and more extensively than participants who received disconfirming feedback. Past research has focused almost exclusively on the negative impact of post-identification feedback. However, given the differences between recalling information during an investigative interview and identifying a perpetrator in a lineup, there may be situations in which feedback may help build rapport and thus actually be beneficial.

Providing confirming feedback may decrease cognitive load during a subsequent recall attempt, and thus allow for a more thorough memory search. A decrease in cognitive load would be particularly beneficial if the information provided during the first recall attempt was accurate, particularly given the perceived credibility of confident witnesses in the criminal justice system (Bradfield \& Wells, 2000; Brewer \& Burke, 2002). Neutral and no feedback are not expected to significantly increase or decrease cognitive load. However, there may be a marginal difference between participants who are given neutral feedback and participants given no feedback considering that the neutral feedback condition could be perceived as an instance of rapport building, and participants in the no feedback condition would likely not have the same experience.

Finally, providing disconfirming feedback was predicted to render a witness less resistant to the subsequent introduction of misinformation and more inaccurate in their source monitoring decisions. For example, if witnesses have been told that they have 
provided incorrect information during an initial memory test (e.g., an investigative interview) and those witnesses are later introduced to misinformation (e.g., through the use of suggestive questions), those witnesses may rely more on the misinformation given by the interviewer because the witnesses believe that their source monitoring decision making has been compromised.

Hypothesis two. The second hypothesis predicted that participants receiving confirming post-recall feedback would have the highest confidence in both accurate and inaccurate information recalled compared to participants receiving no, neutral or disconfirming feedback, and that participants receiving no or neutral feedback would have higher confidence ratings compared to participants receiving disconfirming feedback. Offering confirming feedback to participant witnesses has consistently been shown to increase confidence (Wells \& Bradfield, 1998; 1999).

The increase in confidence after confirming feedback is given may be partially the result of hindsight bias (Fischhoff, 1977) and has also been explained by the SCIF (Charman et al., 2010). Specifically, if witnesses receive confirming feedback from a credible source, witnesses will be more likely to incorporate that feedback when making a judgment of their confidence. Although disconfirming feedback had not been shown to have a "symmetrical" deleterious effect on confidence compared to confirming feedback, research suggests that disconfirming feedback can be detrimental to witness confidence (Douglas \& Steblay, 2006; Steblay et al., 2014; Wells \& Bradfield, 1998). It was also predicted that confirming feedback would have a bolstering effect on the length of time participants reported viewing the perpetrator, their reported ease of recall, their attention paid to the perpetrator, and their perception of accuracy of their recall compared to 
participants receiving neutral, no, and disconfirming feedback and that participants given neutral feedback were predicted to report better views of the perpetrator and perceive their recall as more accurate compared to participants given disconfirming feedback.

Hypothesis three. The third hypothesis predicted that open-ended questions would elicit the greatest accuracy and quantity of information compared to cued questions. Open-ended questions are considered a staple of best practice investigative interviewing and are consistently recommended in various best practice interviewing methods (e.g., Fisher \& Geiselman, 1992; Orbach et al., 2000; Powell et al., 2005; Technical Working Group for Eyewitness Evidence, 1999; 2003).

Open-ended questions allow witnesses to use and adjust their own output criterion and to recall information in the way it is represented in their memory as well as facilitating active witness participation. Cued questions are potentially valuable in eliciting specific information not previously retrieved during a free recall opportunity without introducing misinformation. It was thus predicted that cued questions would elicit a lower quantity of accurate information than open-ended questions, but more accurate and plentiful information than suggestive questions, as the latter have been consistently shown to be detrimental to witness recall especially when they introduce misinformation, given that memory is a reconstructive process (Lindsay, 1990; Loftus, 1975; Loftus, Miller, \& Burns, 1978; Loftus \& Palmer, 1974; Loftus \& Zanni, 1975; McCloskey \& Zaragoza, 1985).

Hypothesis four. Lastly, feedback and question type were predicted to interact such that participants receiving confirming feedback would be less vulnerable to suggestive questions than participants receiving no or neutral feedback, and participants 
receiving no or neutral feedback would be less vulnerable to suggestive questions than participants receiving disconfirming feedback. Offering confirming feedback to witnesses may improve subsequent recall and resistance to suggestive questions given that confirming feedback may decrease a witnesses' cognitive load. Conversely, witnesses receiving disconfirming feedback may be at increased risk of falsely acquiescing to suggestive questions. Witnesses receiving no or neutral feedback were predicted to be unaffected in their subsequent recall. 


\section{METHOD}

\section{Participants}

Participants were 158 undergraduate students recruited from a large public university in the Southeastern US. The sample size of 158 was determined by a power analysis using $\mathrm{G}^{*}$ Power (Faul, Erdfelder, Lang \& Buchner, 2007) and was found to be sufficient to detect small to medium group differences at $p<.05$ and an experimental power of .95. The sample gathered was primarily female $(78.1 \%, 21.9 \%$ male $)$ and Hispanic (65.6\%, 16.6\% African American, 8.6\% Caucasian, 2.6\% Asian, and 6.6\% reported as "other"). The mean age of participants was $21.66(S D=4.24)$ with a range of 18 to 43 years. Participants were recruited using three methods: 1) posting flyers around both major Florida International University campuses, 2) making announcements in undergraduate classes notifying students of the opportunity to participate, and 3) use of Florida International University's SONA participant recruitment system which advertises research participation studies across classes. All participants were given course credit for participation.

\section{Design}

The study adhered to a 4 (post-recall feedback: confirming v. neutral v. no v. disconfirming) x 2 (question type: open ended v. cued) mixed-factorial design with repeated measures on the last factor.

\section{Procedure and Materials}

Participants arrived individually at a laboratory room and were asked to provide consent to participate and to be video- and audio-recorded. Participants who consented were then instructed how to play a video file of a mock crime video on a computer 
screen. The experimenter told the participant that they were being given instructions on how to proceed because the experimenter would be leaving them alone in the room while they watched the video. Before leaving the room, the experimenter told the participant that s/he had never watched the DVD.

The mock crime DVD has been successfully used in prior research (Kieckhaefer, 2014), was 2 minutes and 26 seconds long, and depicted a video-recorded realistic convenience store armed robbery (Appendix B). The crime was filmed from a "point of view" perspective. That is, when watching the DVD, it appears as if the participant was watching from the viewpoint of someone who was actually walking into a convenience store and witnessing the robbery. The mock crime depicted three witnesses including a female customer, a male customer, a female cashier, and a male robber.

The video first featured the cashier who was a 20-year-old Hispanic female with brown eyes and long black hair worn straight down behind her shoulders and fastened with a bow on the left side of her head. She wore a pink cardigan over a white shirt, dark skirt, and glasses with black frames. Throughout the video, the cashier looked at and pressed buttons on her phone and shifted her weight from foot to foot. After focusing on the cashier for three seconds, the camera shifted to a 19-year-old Caucasian female customer who entered the store carrying a small black and white puppy. She was wearing a light blue t-shirt, light grey shorts, a multi-colored purse across her body, glasses, and sandals.

After entering, the female customer walked to the back of the store, picked up an energy drink in a large green can, walked to the front of the store, paid with cash, and exited the store. As the female customer approached the cashier, the male customer 
entered the store. The male customer was a 23-year-old Hispanic male with short black hair and brown eyes. He was wearing glasses with black frames, a brown collared shirt, blue jeans, and black boots. After entering, the male customer walked to the back of the store and took a red Gatorade out of a refrigerator. He then moved to the last aisle in the store where he began looking at granola bars. While the male customer examined the granola bars, the perpetrator entered the store. The perpetrator was a 23 -year-old Hispanic male with short black hair and light facial hair. He had brown eyes and was wearing a black hooded sweatshirt, a green shirt underneath the sweatshirt, dark blue jeans, and dark blue tennis shoes.

After the perpetrator entered the store, he took off his sunglasses, put them in his sweatshirt pocket, and then zipped up his hooded sweatshirt. He then walked to an open refrigerated case where he picked up a purple Naked brand smoothie. The perpetrator then circled through the store, approached the cashier and asked, "Do you have any cigarettes?" The cashier replied, "No, sorry," and the perpetrator then pulled out a toy black $9 \mathrm{~mm}$ gun and pointed it at the cashier. The perpetrator then yelled, "Give me all your money!" and turned to the male witness and said, "Hey you, get over there, hands up!" As the perpetrator was ordering the male witness to come to the front of the store, the cashier produced a black bag from behind the counter and put money from the register into the bag. As the cashier filled the bag with money, the perpetrator yelled, “Let's go, let's go! I don't got all day, let's go!” The cashier then handed the perpetrator the bag and he quickly ran out of the store while yelling, "I don't want no funny business!" 
After the participant finished watching the video, the experimenter re-entered the room. To make sure experimenters did not re-enter the room before participants finished watching the video, they were given stop watches timed to the length of the video. Once the experimenter re-entered the room, participants were given a distraction task to prevent ceiling effects of accuracy on cued-questions. The use of the distraction task was dictated by the results of a pilot study $(N=30)$. Given that an accuracy rate of $.75 \mathrm{might}$ not have allowed for the examination of meaningful differences between participant recall from cued questions as a function of feedback, a ten minute distraction task was given.

The distractor task was a series of number connection puzzles (see Appendix C for a sample of a number connection puzzle). Participants were told, "You will now be given a cognitive ability task. You will have ten minutes to complete as many of the puzzles as possible. You have ten minutes beginning now." Experimenters used a stop watch to ensure that all participants worked on completing the puzzles for exactly ten minutes. After participants worked on the distractor task for ten minutes, the experimenter proceeded with the first interview.

During the first interview, the experimenter interviewed the participant using a set of four open-ended questions (Appendix D). Participants were first asked, "Tell me everything you can remember about what you just witnessed," and were then given three follow-up questions in random order: 1) "Tell me everything you can remember about the perpetrator," 2) Tell me everything you can remember about the location of the crime," and 3) “Tell me everything you can remember about any witnesses.” These questions were followed by the final question: "Is there anything else you can remember?" To 
ensure exhaustive recall, the last question was repeated until participants explicitly stated that they could not remember anything else.

After participants explicitly stated that they could not remember anything else, they were asked a series of 18 cued questions in random order (Appendix E). For example, participants were asked, "What color were the frames of the glasses the cashier was wearing?", "What was the race of the perpetrator?", and "What was the first thing the perpetrator touched in the store?" Similar to real-world investigative interviews, these questions were aimed at eliciting specific details of the mock-crime that may have not been reported during free recall. These questions were followed by the final question: "Is there anything else you can remember?" which was repeated by the interviewer until participants explicitly stated that they could not remember anything else.

Upon completion of the first witness interview, the interviewer provided participants with feedback (confirming, neutral, disconfirming, or none) according to their pre-assigned, randomly selected feedback condition. The specific operationalization of the feedback was chosen to avoid giving any clues about the source of the interviewer's information and to avoid giving information about the credibility or authority of the interviewer, which could have possibly confounded the effects of postrecall feedback. That is, the use of general rather than specific feedback was employed to maximize experimental control over the type of feedback in light of varying witness reports. Regardless of what type of information the participant recalled, the feedback universally applied and did not have to be tailored to the information given by any participant. Further, the four feedback conditions were designed in such a way that the experimenter was speaking for approximately the same length of time. Research 
assistants were trained to provide feedback in a casual, conversational manner without sounding rehearsed.

Participants who received confirming feedback were told by the experimenter, “Although I haven't watched the video, I’ve been given information about the video from the experimenters in charge of the study and the information you've given me seems to be accurate." Conversely, participants given disconfirming feedback were told, “Although I haven't watched the video, I've been given information about the video from the experimenters in charge of the study and the information you've given me seems to be inaccurate." Participants in the neutral feedback condition were told: "Thank you for your statement. I appreciate you taking the time to provide the information that you did. I think I have everything I need for now." Lastly, participants receiving no feedback were told: "Let me just check the time before we continue. I want to make sure that we're staying on track and that I collect all the information I need to. The experimenters are strict with the procedure.” The current design included both neutral and no feedback in order to explore the potential for participants to interpret neutral feedback as rapport building that can potentially impact subsequent information given by witnesses.

After feedback was given, participants were asked to give verbal ratings of the perceived accuracy of their overall statement, the confidence in the accuracy of their recall, attention paid to the perpetrator, quality of view of the perpetrator, length of time they were able to see the perpetrator, and the ease with which they recalled information during the interview (Appendix F). To help each participant conceptualize the 7-point Likert-type scale on which level of attention paid to the perpetrator, quality of view of the perpetrator, confidence in recall accuracy, ease of recall, and perception of recall 
accuracy were measured, the experimenter gave the participant a laminated form listing a 7-point Likert-type scale with no labels for specific measures (Appendix G). After these ratings, the experimenter told participants that there were a few more questions $\mathrm{s} / \mathrm{he}$ needed to ask before the study could be completed. The experimenter then casually looked over at the camera, began to look concerned, started examining the camera, and told the participant that it appeared the camera had malfunctioned and had not been recording for the duration of the interview (although it had in fact recorded). The experimenter then explained that because the camera had not been recording, $\mathrm{s} /$ he needed to re-interview the participant as well as re-collect reports of confidence, attention, qualify of view, length of time the perpetrator was seen, and ease of recall. The deception allowed the experimenter to subsequently conduct a second interview in an identical format without revealing the true purpose of the study or arousing suspicion from the participant. The interviewer then conducted the second interview.

For Interview 2, participants were asked the same open-ended and cued questions given during Interview 1 as well as a new series of 20 suggestive questions which introduced misinformation through modification (Appendix H). One half of the questions were accurate-leading and the other half was incorrect-leading which was counterbalanced across participants. For example, "Did the robber have any facial hair?" was an accurate-leading question given that the perpetrator had facial hair whereas, "Was the robber clean shaven?" was an inaccurate-leading question.

Once Interview 2 was completed, participants were again asked to give verbal reports of confidence, perception of overall recall accuracy, attention to the perpetrator, quality of view, ease of recall, and the amount of time they saw the perpetrator, but as it 
related to the second interview. The experimenter explained that s/he was going to collect the data again just to make sure it was recorded by the camera. Asking for a second set of self-report measures about the second recall opportunity allowed for a test of any possible changes in the self-report data that may occur as a function of feedback. After the selfreport data was collected, participants were asked to complete a source monitoring questionnaire that included a set of 20 source monitoring questions presented in random order (Appendix I). Each source monitoring question reflected the items included in each of the suggestive-leading questions. For each source monitoring item, participants were first asked to answer a cued question (e.g., "What color was the gun?") before being asked about source of the information provided. For each item, participants were asked whether they remembered the information from the interviewer only, the video only, both the interviewer and the video, or if the source was unknown. If participants responded, "don't know" to the cued source monitoring items, they were not asked about the source of the information given that the information was not known. Participants were asked both about their confidence in the accuracy of their responses to the cued questions and in the confidence in their ability to correctly identify the source of the information. Source monitoring confidence was collected on a 7-point Likert-type scale with "1" being "Not at all confident" and "7" being "Extremely confident."

After completing the source monitoring questionnaire, participants were provided with a rapport questionnaire to assess whether post-recall feedback affected witnesses' perceptions of rapport with the interviewer (Appendix J). Participants were also given a questionnaire to examine their cognitive load (Kieckhaefer, 2014) which helped address the theoretical question of whether feedback impacts perceived cognitive load during a 
subsequent recall opportunity (Appendix K). Lastly, suspicion was assessed (Appendix L). Specifically, participants were asked what the experimenter said during the interviews, whether they believed that the experimenter did not see the video, and whether there was deception involved in the study and, if so, in what way(s) (see Appendix M for overall study design).

\section{Interview Coding}

All witness interview audio recordings collected from participants were transcribed. Each interview transcript was then coded by two independent scorers. Both scorers who were blind to participants' conditions and extensively trained in using a detailed set of scoring rules. After thorough training of coding procedures was completed by each scorer, interview transcripts were coded by each scorer independently. A primary scorer coded all participant interviews and the co-scorer independently coded $50(31.6 \%)$ of the transcribed interviews to establish inter-rater reliability. Intra-class correlations revealed high inter-rater reliability for all dependent variables assessed from the interviews. Specifically, intra-class correlations ranged from .93 to .99.

\section{Outcome Variables}

For scoring purposes, open-ended and cued witness portions of each interview transcript were divided into units of information. A unit was defined as the smallest piece of information that could assist in investigating a crime. That is, in the current study, units were considered "meaningful" parts of a sentence.

By segmenting recall into individual units, coders were able to evaluate each unit for accuracy individually. For example, if the robber was described as a Caucasian male, "Caucasian" and "male" were divided into two separate units and assessed separately. 
Quantity of information was assessed both via a word count for each section and by adding up the number of units per interview transcript. Each unit was then scored as accurate, inaccurate, "don't know," subjective, repeated, or a not scorable answer.

A unit was scored as accurate if it depicted an accurate reflection of what was presented in the video and scored as inaccurate if it represented an inaccurate reflection (either modification or addition/confabulation) of what was depicted. A response was recorded as a "don't know" unit if a participant indicated that he or she did not know the answer. A unit was classified as subjective if a participant offered a response that was an opinion of the participant that could not be verified for accuracy (e.g., "I thought the perpetrator was extremely attractive!"). A response was scored as a repeated unit if it had already been mentioned at any previous point in time during the interview. Scoring for repeated units during an interview included both open-ended and cued questions. For example, if a participant stated that the female customer was Caucasian in response to the first open-ended question and then stated again that the female customer was Caucasian in response to a subsequent cued question in the same interview, this was classified as a repeated unit. A not scorable answer was defined as a response by a participant that was irrelevant to the recall of the mock crime video. For example, if the participant stated, "I think it's cold in here" or "I am feeling really tired," these were considered not scorable units.

Percent accuracy was computed by adding up the number of accurate units reported and dividing them by the total number of accurate, inaccurate, and "don't know" units. Subjective and not scorable data were not included as part of that analysis. Percent inaccuracy was computed by adding up the number of inaccurate units and dividing those 
by the total number of accurate, inaccurate, and “don't know" units. Percent of "don't know" units were assessed by dividing the number of "don't know" units by the number of accurate, inaccurate, and "don't know" units. Percent of repeated units was computed by dividing the total number of "repeated units" by the total number of reported units (accurate, inaccurate, “don't know," repeated, and subjective). Percent of subjective units was computed by adding up the total number of subjective and dividing each category of units by the total number of reported units.

Answers to suggestive questions were scored according to a detailed answer key. If the response from the participant was accurate, it was either classified as 1) a correct acquiescence or 2) a correct rejection of interviewer's suggestion. If the response was inaccurate, it was either classified as 1) an incorrect acquiescence which is agreeing with the interviewer's incorrect suggestive question or 2) an incorrect rejection which is disagreeing with correct information suggested by the interviewer. Rate of correct acquiescences was computed by adding up the number of correct acquiescence responses and dividing that by the number of total number of responses gathered via suggestive questions. Rate of correct rejections was computed by adding up the number of correct rejections and dividing that by the number of total responses gathered by suggestive questions. Rate of incorrect acquiescences was analyzed by dividing the total number of incorrect acquiescence responses and dividing that by the total number of responses elicited via suggestive questions. Rate of incorrect rejections was computed by adding up the number of incorrect rejection responses and dividing that by the total number of responses elicited via suggestive questions. 
Inconsistencies between the interviews were established by first comparing each detail reported in Interview 1 with that same detail in Interview 2. For example, if during Interview 1 a participant claimed that the perpetrator had facial hair, but in Interview 2 claimed the perpetrator was clean shaven, this was considered inconsistent. Inconsistencies within interviews were not examined. Type of inconsistency was also documented. Specifically, scorers kept track of the type of inconsistency between Interview 1 and Interview 2: from accurate to inaccurate, from inaccurate to accurate, or from inaccurate to inaccurate. An example of the type of inconsistency classified as accurate to inaccurate would be if, during Interview 1, a participant accurately recalled the perpetrator was a Hispanic male, but during Interview 2 recalls the perpetrator was a Caucasian male. An inconsistency from inaccurate to accurate was classified as such if a participant incorrectly recalled that there were five witnesses in the convenience store at the time of the robbery, but during Interview 2 the witness accurately recalled that there were two witnesses. An inaccurate to inaccurate inconsistency was scored if, during Interview 1, a participant recalled that the perpetrator was an African American male (inaccurate) and in Interview 2 recalled that the perpetrator was Caucasian (inaccurate).

Reminiscence was also measured by documenting information that was recalled in Interview 2 but not recalled during Interview 1. Reminiscent information was also scored for accuracy. Forgotten information and the accuracy of forgotten information were also scored. Specifically, forgotten information was classified as such if a participant recalled information in Interview 1 and did not recall that information during Interview 2.

Uncertain units were also assessed and put into two categories: 1) uncertain accurate or 2) uncertain inaccurate. An uncertain accurate unit was classified as such if participants 
indicated that they were not sure if an answer, but offered an accurate answer anyway. For example, if a participant stated, "I'm not sure, but I think the robber was Hispanic," this was classified as an uncertain accurate unit. Conversely, if a participant stated, "I don't know, but I think the robber was African American,” this was classified as uncertain inaccurate.

Length of time participants reported viewing the perpetrator was measured in number of seconds. Quality of view the participant reported having of the perpetrator was verbally reported by the participant on a 7-point Likert-type scale with "1" being "Extremely poor" and "7" being "Extremely clear." Level of attention the participant reportedly paid to the perpetrator was verbally reported by the participant on a 7-point Likert-type scale with "1" being "Extremely low" and "7" being "Extremely high." The reported confidence in recall accuracy was verbally reported by the participant on a 7point Likert-type scale with "1" being "Extremely not confident" and "7" being "Extremely confident." The reported ease of recalling the information was verbally reported by the participant on a 7-point Likert-type scale with "1" being "Not at all easy" and "7" being "Extremely easy." Perception of recall accuracy was verbally reported by the participant on 7-point Likert-type scale with "1" being "Extremely inaccurate" and "7" being "Extremely accurate" (see Appendix F for the script experimenters used to collect the self-reported measures).

Lastly, source monitoring responses were analyzed to assess whether participants correctly or incorrectly attributed a piece of information coming from: 1) the crime video only, 2) the interviewer only, 3) both the crime video and the interviewer, or 4) or an 
uncertain source. Participants were also asked about their confidence in identifying a source on a Likert-type scale from 1 (not at all confident) to 7 (extremely confident). Correct source monitoring attributions were classified and counted as a unit of information whose source was correctly identified. For example, if the crime video was the only source of information conveying that the perpetrator kept the gun in his the back of his pants and the participant identified the crime video as being the source of the information, this was considered a correct source monitoring attribution. Answers were classified as incorrect source monitoring attributions if a participant misattributed the source of a piece of information. For example, if the interviewer was the only source of information suggesting that the perpetrator was Caucasian, but the participant indicated the crime video as the source of the information, this was classified as an incorrect source monitoring attribution. The proportion of correct source monitoring attributions was computed as the total number of items assigned to the correct source out of all source monitoring items and the proportion of incorrect source monitoring attributions was computed as the total number of items assigned to the incorrect source out of all source monitoring items. 


\section{Results}

\section{Impact of Post-Recall Feedback on Witness Confidence and Reports of View}

First assessment. To examine the possible impact of feedback on the first assessment of witness confidence and reports of view of the perpetrator, a one-way MANOVA was conducted. The independent variable in the current analysis was the type of feedback given to the participant (confirming v. neutral v. none v. disconfirming) and the dependent variables were the first assessment of the length of time the participant reported viewing the perpetrator, the clarity of view the participant reported having of the perpetrator, the level of attention the participant reportedly paid to the perpetrator, the reported confidence in prior recall accuracy, the reported ease of recalling the information, and the perception of recall accuracy (see Table 1 for means and standard deviations of reports of view of the perpetrator, reported confidence, reported ease of recall, and perceived accuracy of recall by feedback condition).

The one-way MANOVA revealed a statistically significant overall difference across feedback conditions, $F(3,155)=3.28, p<.001, \eta_{p}^{2}=.134$. Specifically, feedback had a statistically significant effect on the reported clarity of view of the perpetrator, $F(3$, $155)=4.98, p=.003, \eta_{p}^{2}=.102$. Post hoc Tukey tests revealed that participants given confirming feedback reported a significantly clearer view of the perpetrator than participants given disconfirming feedback $(p=.002)$.

The MANOVA also revealed a significant difference between feedback conditions for participants' reported confidence in recall accuracy, $F(3,155)=10.89, p<$ $.001, \eta_{p}^{2}=.198$. A subsequent Tukey analysis revealed that participants given confirming feedback were more confident in the accuracy of their prior recall compared to 
participants given neutral feedback $(p=.037)$, participants given confirming feedback were more confident compared to participants given no feedback $(p=.043)$, participants given confirming feedback were more confident compared to participants given disconfirming feedback $(p<.001)$, participants given neutral feedback were more confident compared to participants given disconfirming feedback $(p=.031)$, and participants given no feedback were more confident compared to participants given disconfirming feedback $(p=.015)$. There was no significant difference in reported confidence between participants who received neutral feedback and those who received no feedback $(p=.998)$.

The MANOVA further revealed a significant difference between feedback conditions for participants' reported ease of recall, $F(3,155)=10.94, p<.001, \eta_{\mathrm{p}}^{2}=$ .199. According to post hoc Tukey tests, participants given confirming feedback reported easier recall compared to participants given neutral feedback $(p=.005)$, participants given confirming feedback reported easier recall compared to participants given no feedback $(p=.003)$, and participants given confirming feedback reported easier recall compared to participants who received disconfirming feedback $(p<.001)$. There were no other significant differences (all $p s>.05$ ).

The MANOVA further revealed a significant difference between feedback conditions for perceived recall accuracy, $F(3,155)=14.01, p<.001, \eta_{\mathrm{p}}^{2}=.242$. Post hoc Tukey tests showed that participants given confirming feedback perceived their recall to be more accurate compared to participants given neutral feedback $(p=.003)$, no feedback $(p=.001)$, and disconfirming feedback $(p<.001)$. Participants given neutral feedback perceived their recall to be more accurate compared to participants given disconfirming 
feedback $(p=.002)$, and participants given no feedback perceived their recall to be more accurate compared to participants given disconfirming feedback $(p=.002)$. There was no significant difference in perception of recall accuracy between participants given neutral and no feedback $(p=.910)$.

There was no significant effect of feedback on length of time participants reported viewing the perpetrator, $F(3,155)=.945, p=.421, \eta_{\mathrm{p}}^{2}=.021$. There was also no significant effect of feedback on the level of attention participants reported paying to the perpetrator, $F(3,155)=.372, p=.773, \eta_{\mathrm{p}}^{2}=.008$.

Table 1

First assessment of mean reports of view of the perpetrator, reported confidence, reported ease of recall, and perceived accuracy of recall

\begin{tabular}{|c|c|c|c|c|c|c|c|c|}
\hline \multirow{3}{*}{ First Assessment } & \multicolumn{8}{|c|}{ Feedback Received } \\
\hline & \multicolumn{2}{|c|}{ Confirming } & \multicolumn{2}{|c|}{ Neutral } & \multicolumn{2}{|c|}{ None } & \multicolumn{2}{|c|}{ Disconfirming } \\
\hline & $\mathrm{M}$ & $\mathrm{SD}$ & $M$ & SD & $\mathrm{M}$ & $\mathrm{SD}$ & $\mathrm{M}$ & $\mathrm{SD}$ \\
\hline Length of view ${ }^{\mathrm{a}}$ & 48.10 & 65.54 & 31.77 & 29.64 & 37.91 & 35.29 & 47.70 & 41.46 \\
\hline Quality of view & $5.34 *$ & 1.26 & 4.60 & 1.16 & 5.00 & 1.19 & 4.23 & 1.45 \\
\hline Attention & 5.59 & 1.24 & 5.30 & 1.26 & 5.51 & 1.01 & 5.37 & 1.33 \\
\hline Confidence & $5.68 *$ & 1.13 & $4.83 *$ & 1.32 & $4.89 *$ & 1.39 & 3.90 & 1.40 \\
\hline Ease of recall & $5.34 *$ & 1.20 & 4.37 & 1.07 & 4.37 & 1.14 & 3.77 & 1.33 \\
\hline Perceived accuracy & $5.71 *$ & 0.90 & $4.83 *$ & 0.99 & $4.80 *$ & 1.32 & 3.87 & 1.50 \\
\hline
\end{tabular}

${ }^{2}$ Length of view was reported in number of seconds

*Denotes significant effect at $p<.05$

Second assessment. To examine the possible impact of feedback on the second assessment of witness confidence and reports of view of the perpetrator, after the second recall opportunity, a one-way MANOVA was again conducted. The independent variable was the type of feedback (confirming vs. disconfirming vs. neutral vs. no feedback) given to the participant and the dependent variables were the second round of assessments of length of time the participant reported viewing the perpetrator, the clarity of view the participant reported having of the perpetrator, the level of attention the participant 
reportedly paid to the perpetrator, the reported confidence in recall accuracy, the reported ease of recalling the information, and the perception of recall accuracy. It is important to note that the self-report data gathered during the second assessment applied only to Interview 2 as participants were specifically instructed to give these measures only as they applied to the second recall attempt (see Table 2 for means and standard deviations of reports of view of the perpetrator, reported confidence, reported ease of recall, and perceived accuracy of recall by feedback condition).

The one-way MANOVA again revealed an overall effect of feedback, $F(3,155)=$ $3.28, p<.001, \eta_{p}^{2}=.133$. Specifically, there was an effect of feedback on the reported clarity of view of the perpetrator, $F(3,155)=4.84, p=.003, \eta_{p}^{2}=.099$. Post hoc Tukey analyses revealed that participants who received confirming feedback reported having a significantly clearer view of the perpetrator compared to participants who received disconfirming feedback $(p=.003)$.

The MANOVA also revealed a significant difference between feedback conditions for participants' reported confidence in recall accuracy, $F(3,155)=9.42, p<$ $.001, \eta_{p}^{2}=.176$. Subsequent Tukey tests revealed that participants given confirming feedback were more confident compared to participants given neutral feedback ( $p=$ $.005)$, no feedback $(p=.048)$, and compared to participants given disconfirming feedback $(p<.001)$. Participants given no feedback were more confident compared to participants given disconfirming feedback $(p=.049)$, with no additional difference in reported confidence between participants given neutral feedback and participants given no feedback $(p=.823)$ and between participants given neutral and disconfirming feedback $(p=.355)$ 
The MANOVA further revealed a significant difference between feedback conditions for participant reported ease of recall, $F(3,155)=7.73, p<.001, \eta_{\mathrm{p}}^{2}=.149$. Subsequent Tukey tests showed that participants given confirming feedback reported easier recall compared to participants given neutral feedback $(p=.003)$, compared to participants given no feedback $(p=.045)$, and compared to participants who received disconfirming feedback $(p<.001)$. There was no significant difference in reported ease of recall between participants given neutral feedback and participants given no or disconfirming feedback ( $p=.731$ and $p=.872$, respectively), and no difference between participants given no and disconfirming feedback $(p=.267)$.

As to perception of recall accuracy, the MANOVA further revealed a significant difference between feedback conditions for perceived second recall accuracy, $F(3,155)=$ 15.6, $p<.001, \eta_{\mathrm{p}}^{2}=.261$. Follow-up Tukey tests showed that participants given confirming feedback perceived their recall to be more accurate compared to participants given neutral feedback $(p=.005)$, no feedback $(p=.014)$, and compared to participants given disconfirming feedback $(p<.001)$. Participants given neutral feedback perceived their recall to be more accurate compared to participants given disconfirming feedback ( $p$ $=.011$ ), and participants given no feedback perceived their recall to be more accurate compared to participants given disconfirming feedback $(p=.002)$. There was no significant difference in perception of second recall accuracy between participants given neutral feedback and no feedback $(p=.966)$.

There was no significant effect of feedback on length of time participants reported viewing the perpetrator, $F(3,155)=1.49, p=.221, \eta_{p}^{2}=.033$, or on the level of attention participants reported paying to the perpetrator, $F(3,155)=1.08, p=.360, \eta_{\mathrm{p}}^{2}=.024$. 
Table 2

Second assessment of mean reports of view of the perpetrator, reported confidence, reported ease of recall, and perceived accuracy of recall

\begin{tabular}{lcccccccc}
\hline \multirow{2}{*}{ First Assessment } & \multicolumn{9}{c}{ Confirming } & \multicolumn{3}{c}{ Neutral } & \multicolumn{3}{c}{ None } & \multicolumn{2}{c}{ Disconfirming } \\
\cline { 2 - 10 } & $\mathrm{M}$ & $\mathrm{SD}$ & $\mathrm{M}$ & $\mathrm{SD}$ & $\mathrm{M}$ & $\mathrm{SD}$ & $\mathrm{M}$ & $\mathrm{SD}$ \\
\hline Length of view $^{\mathrm{a}}$ & 47.39 & 65.65 & 27.47 & 24.57 & 38.49 & 34.30 & 49.30 & 41.44 \\
Quality of view & $5.39^{*}$ & 1.20 & 4.67 & 1.03 & 5.06 & 1.03 & 4.37 & 1.50 \\
Attention & 5.63 & 1.02 & 5.17 & 1.18 & 5.46 & 1.17 & 5.27 & 1.39 \\
Confidence & $5.59^{*}$ & 1.02 & 4.63 & 1.10 & $4.89^{*}$ & 1.23 & 4.13 & 1.36 \\
Ease of recall & $5.29^{*}$ & 1.29 & 4.27 & 1.11 & 4.57 & 1.07 & 4.03 & 1.25 \\
Perceived accuracy & $5.61^{*}$ & 1.02 & $4.70^{*}$ & 0.92 & $4.83^{*}$ & 1.07 & 3.80 & 1.40 \\
\hline
\end{tabular}

${ }^{\mathrm{a}}$ Length of view was reported in number of seconds

*Denotes significant effect at $\mathrm{p}<.05$

Differences between first and second assessment. To determine possible

differences between the first assessment and second assessment in the length of time the participant reported viewing the perpetrator, the clarity of view the participant reported having of the perpetrator, the level of attention the participant reportedly paid to the perpetrator, the reported confidence in recall accuracy, the reported ease of recalling the information, and the perception of recall accuracy, a within-participants repeated measures MANOVA was conducted. Analyses revealed no differences between the first and second assessment for any of the self-reported measures, $F(3,155)=0.46, p=.807$, $\eta_{\mathrm{p}}^{2}=.003$. That is, participants did not significantly change their confidence, their selfreported measures of view of the perpetrator, or ease of recall from the first assessment of these measures to the second assessment of these measures.

\section{Impact of Question Type and Post-Recall Feedback on Witness Recall}

A mixed-measures MANOVA was used to test for interactions as well as main effects of question type and post-recall feedback on Interview 2 quantity and accuracy. The independent variables were the between-participants variable of feedback (confirming vs. neutral vs. no vs. disconfirming) and the within-participants variable of 
question type (open-ended vs. cued). The dependent variables in the current analysis were the total number of accurate units recalled, the overall accuracy rate, the total number of inaccurate units recalled, the overall inaccuracy rate, the total number of "don't know" units, number of repeated units, number of subjective responses, and number of not scorable responses. There was a significant main effect of question type on witness accuracy, $F(3,155)=2.59, p=.033, \eta^{2} \mathrm{p}=1.23$. A subsequent Tukey test revealed that participants reported more accurate units of information when responding to open-ended questions compared to cued questions $(p=.020)$. Further, participants' accuracy rates were higher when responding to open-ended questions compared to cued questions ( $p=$ .045). There was also a significant main effect of question type on the quantity of witness recall, $F(3,155)=1.91, p=.040, \eta_{\mathrm{p}}^{2}=.923$. A post hoc Tukey analysis showed that participants reported more overall units of information when responding to open-ended questions compared to cued questions $(p=.034)$. However, there was no significant main effect of the type of feedback that was offered on any of the dependent variables, $F(3$, $155)=.961, p=.415, \eta_{\mathrm{p}}^{2}=.022$. There was also no significant interaction between the type of feedback offered and the type of question used for any of the dependent variables, $F(3,155)=1.09, p=.888, \eta_{p}^{2}=.024$.

Further, to examine the impact of question type on recall during Interview 1 (prefeedback), a one-way MANOVA was conducted which examined the total number of accurate units recalled, the overall accuracy rate, the total number of inaccurate units recalled, the overall inaccuracy rate, the total number of "don't know" units, number of repeated units, number of subjective responses, and number of not scorable responses. The one-way MANOVA revealed a significant effect of question type on witness recall, 
$F(3,155)=1.85, p=.035, \eta_{\mathrm{p}}^{2}=.888$. Specifically, a post hoc Tukey analysis showed that participants reported more overall units of information when responding to openended questions compared to cued questions $(p=.035)$.

Table 3

Total number of units and mean percentages participants' responses in Interview 2 by feedback and question type

\begin{tabular}{|c|c|c|c|c|c|c|c|c|}
\hline \multirow[b]{2}{*}{ Unit type } & \multicolumn{2}{|c|}{ Confirming } & \multicolumn{2}{|c|}{ Neutral } & \multicolumn{2}{|c|}{ None } & \multicolumn{2}{|c|}{ Disconfirming } \\
\hline & Open & Cued & Open & Cued & Open & Cued & Open & Cued \\
\hline Accurate $\%{ }^{\mathrm{a}}$ & 82.4 & 57.7 & 74.6 & 62.9 & 73.5 & 55.9 & 75.3 & 57.1 \\
\hline Accurate $\#^{\mathrm{b}}$ & 61 & 15 & 59 & 17 & 50 & 19 & 55 & 16 \\
\hline Inaccurate $\%$ & 13.5 & 26.9 & 19.0 & 29.6 & 17.6 & 29.4 & 17.8 & 32.1 \\
\hline Inaccurate \# & 10 & 7 & 15 & 8 & 12 & 10 & 13 & 9 \\
\hline Don't know \% & 4.05 & 15.4 & 19.0 & 7.40 & 8.80 & 14.7 & 6.80 & 10.7 \\
\hline Don't know \# & 3 & 4 & 5 & 2 & 6 & 5 & 5 & 3 \\
\hline Repeated \# & 21 & 5 & 19 & 8 & 18 & 2 & 16 & 4 \\
\hline Subjective \# & 7 & 3 & 9 & 5 & 8 & 4 & 8 & 2 \\
\hline Not scorable \# & 17 & 3 & 14 & 2 & 15 & 4 & 15 & 5 \\
\hline Word count & 980 & 100 & 899 & 113 & 950 & 109 & 871 & 102 \\
\hline Total units & 119 & 37 & 121 & 42 & 109 & 44 & 112 & 39 \\
\hline
\end{tabular}

${ }^{\mathrm{a}} \%$ refers to the percentage of units divided by the total number of units

$\mathrm{b}$ \# refers to the number of units

\section{Impact of Feedback on Consistency and Uncertain Information}

To determine a possible effect of feedback type on consistency between Interview 1 and Interview 2, a one-way MANOVA was conducted. The independent variable in this analysis was the type of feedback given and the dependent variables were the number of reminiscent units, forgotten units, uncertain units, and contradictions between witness recall at time 1 and time 2 . There was no significant effect of feedback on any of these dependent variables, $F(3,155)=1.82, p=.102, \eta_{\mathrm{p}}^{2}=.088$.

\section{Suggestive Questions}

To determine a possible effect of feedback type on responses to suggestive questions, a one-way MANOVA was conducted. The independent variable in the current 
analysis was the type of feedback given to the participant and the dependent variables were correct acquiescence rate, incorrect acquiescence rate, correct rejection rate, incorrect rejection rate, and “don't know" response rate. There was no significant effect of feedback on participant responses to suggestive questions, $F(3,155)=.922, p=.314$, $\eta_{\mathrm{p}}^{2}=.033$ (see Table 4 for responses to suggestive questions by condition).

Table 4 Mean number of correct acquiescences, correct rejections, incorrect acquiescences, and incorrect rejections

\begin{tabular}{llcc}
\hline Participant Response & Feedback Received & Mean & $\begin{array}{c}\text { Standard } \\
\text { Deviation }\end{array}$ \\
\hline \multirow{3}{*}{ Correct Acquiescence } & Confirming & 9.2 & 2.3 \\
& Neutral & 9.0 & 1.9 \\
& None & 9.3 & 2.5 \\
& Disconfirming & 8.9 & 2.0 \\
& & & \\
Correct Rejection & Confirming & 8.6 & 2.2 \\
& Neutral & 8.9 & 2.1 \\
& None & 9.1 & 2.5 \\
& Disconfirming & 8.9 & 1.8 \\
& & & \\
Incorrect Acquiescence & Confirming & 1.1 & 0.9 \\
& Neutral & 1.2 & 1.5 \\
& None & 1.1 & 0.8 \\
& Disconfirming & 1.3 & 1.2 \\
Incorrect Rejection & Confirming & 1.4 & 1.0 \\
& Neutral & 1.2 & 0.7 \\
& None & 1.4 & 0.7 \\
& Disconfirming & 1.3 & 1.1 \\
\hline
\end{tabular}

\section{Relationship Between Confidence and Accuracy}

Pearson correlations were used to determine possible relationships between the first assessment of confidence in accuracy of recall and actual recall accuracy during Interview 1. There was no significant correlation found between the first measure of confidence and the accuracy of recall during Interview $1, r=0.21, n=158, p=.391$. A 
Pearson correlation was also used to examine the presence of a relationship between perceived accuracy and actual recall accuracy. There was no significant correlation between the first measure of perceived accuracy and the accuracy of recall during Interview $1, r=0.25, n=158, p=.154$.

A Pearson correlation was also conducted to examine any potential relationship between the second assessment of confidence in accuracy of recall and actual recall accuracy during Interview 2. There was no significant correlation between the second measure of confidence and the accuracy of recall during Interview 2, $r=0.31, n=158, p$ $=.199$. A Pearson correlation was also used to examine a possible relationship between perceived accuracy and actual recall accuracy yielding no significant correlation between the first measure of perceived accuracy and the accuracy of recall during Interview 1, $r=$ $0.29, n=158, p=.210$.

\section{Source Monitoring Questionnaire}

Open-ended source monitoring questions. Recall that after answering the series of suggestive questions (e.g., "Was the gun black?"), participants completed the source monitoring questionnaire. This questionnaire began with an open-ended question (e.g., "What color was the gun?") for each of the 20 source monitoring items. For each source monitoring item, participants were then asked to attribute the source to each of these initial open-ended source-monitoring questions. Therefore, both the accuracy of answers to the initial open-ended source monitoring questions (e.g., "What color was the gun?"), and the answers to the subsequent source-monitoring questions were assessed ("Where do you remember encountering this information?"). 
Consequently, a one-way MANOVA was used to determine whether participants' open-ended source monitoring responses were affected by the type of feedback previously given to participants. The independent variable in the current analysis was the type of feedback given to participants and the dependent variables were the rate of accurate responses, the rate of inaccurate responses, and the rate of "don't know" responses to open-ended source monitoring questions. The one-way MANOVA revealed no significant impact of feedback on the accuracy of open-ended source monitoring questions, $F(3,155)=0.59, p=.710, \eta_{\mathrm{p}}^{2}=.008$ (see Table 5 for means and standard deviations of response rates to open-ended source monitoring questions).

Table 5

Rates for percent accurate, inaccurate, and don't know responses to open-ended source monitoring questions

\begin{tabular}{|c|c|c|c|c|c|c|}
\hline \multirow[b]{3}{*}{ Feedback Received } & ates to & pen-E & led S & Mo & oring & estions \\
\hline & \multicolumn{2}{|c|}{ Accurate } & \multicolumn{2}{|c|}{ Inaccurate } & \multicolumn{2}{|c|}{ Don't Know } \\
\hline & $\mathrm{M}$ & $\mathrm{SD}$ & $\mathrm{M}$ & $\mathrm{SD}$ & $\mathrm{M}$ & $\mathrm{SD}$ \\
\hline Confirming & 0.65 & 0.16 & 0.20 & 0.29 & 0.15 & 0.18 \\
\hline Neutral & 0.61 & 0.20 & 0.29 & 0.19 & 0.10 & 0.15 \\
\hline None & 0.60 & 0.30 & 0.26 & 0.24 & 0.14 & 0.11 \\
\hline Disconfirming & 0.60 & 0.26 & 0.23 & 0.19 & 0.16 & 0.13 \\
\hline
\end{tabular}

Confidence in accuracy of open-ended source monitoring questions. To assess the impact of feedback on self-reported confidence for open-ended source monitoring recall accuracy, a one-way ANOVA was used. The independent variable was the type of feedback given to participants and the dependent variable was confidence in the accuracy of open-ended source monitoring recall. The analysis revealed that feedback had a significant effect on participant confidence in source monitoring accuracy recall, $F(3$, $155)=2.53, p=.03$. The subsequent Tukey test revealed that participants given confirming feedback were significantly more confident in their open-ended source 
monitoring recall accuracy compared to participants given disconfirming feedback ( $p=$ .02). There were no other significant effects of feedback on source monitoring recall accuracy (see Table 6 for mean confidence in accuracy of open-ended source monitoring questions).

Table 6 Mean confidence ratings for open-ended source monitoring questions ( 1 = not at all confidence and 7 = extremely confident)

\begin{tabular}{llllr}
\hline & \multicolumn{4}{c}{ Confidence Rating } \\
\hline & \multicolumn{1}{c}{ Accurate } & \multicolumn{3}{c}{ Inaccurate } \\
\cline { 2 - 5 } Feedback Received & $\mathrm{M}$ & $\mathrm{SD}$ & $\mathrm{M}$ & $\mathrm{SD}$ \\
\hline Confirming & $5.55^{*}$ & 1.20 & $5.60^{*}$ & 1.55 \\
Neutral & 4.93 & 1.71 & 4.66 & 1.91 \\
None & 4.90 & 1.40 & 4.59 & 1.78 \\
Disconfirming & 4.01 & 1.72 & 4.15 & 1.29 \\
\hline
\end{tabular}

*Denotes significant difference at $p<.05$

Relationship between open-ended source monitoring recall accuracy and

confidence. To examine a possible relationship between accuracy of responses to openended source monitoring questions and confidence in accuracy of responses to openended source monitoring questions, a Pearson correlation was computed. There was no significant correlation between source monitoring recall accuracy and confidence in source monitoring recall accuracy, $r=0.29, n=158, p=.155$.

Source monitoring accuracy. The next set of analyses tested participants' ability to identify the source (e.g., the mock crime video) of the information they recalled in response to the open-ended source monitoring recall questions (e.g., "What color was the gun?") and whether feedback affected participant source monitoring ability. To examine whether feedback impacted source monitoring accuracy, a one-way MANOVA was conducted. The independent variable was the type of feedback given to participants and the dependent variables were the rates of correct source identification, incorrect source 
identification, and “don't know” source identification responses. A one-way MANOVA revealed no significant impact of feedback on source identification accuracy, $F(3,155)=$ $.970, p=.528, \eta_{\mathrm{p}}^{2}=.003$.

Table 7

Source monitoring accuracy, inaccuracy, and don't know response rates

\begin{tabular}{|c|c|c|c|c|c|c|}
\hline \multirow[b]{3}{*}{ Feedback Received } & \multicolumn{6}{|c|}{ Source Identification Rate } \\
\hline & \multicolumn{2}{|c|}{ Accurate } & \multicolumn{2}{|c|}{ Inaccurate } & \multicolumn{2}{|c|}{ Don't Know } \\
\hline & $\bar{M}$ & $\mathrm{SD}$ & $\bar{M}$ & $\mathrm{SD}$ & $\mathrm{M}$ & $\mathrm{SD}$ \\
\hline Confirming & 0.67 & 0.22 & 0.23 & 0.32 & 0.10 & 0.29 \\
\hline Neutral & 0.59 & 0.29 & 0.30 & 0.33 & 0.11 & 0.30 \\
\hline None & 0.64 & 0.25 & 0.25 & 0.19 & 0.11 & 0.11 \\
\hline Disconfirming & 0.61 & 0.33 & 0.23 & 0.27 & 0.16 & 0.23 \\
\hline
\end{tabular}

Confidence in source monitoring accuracy. To assess the impact of feedback on self-reported confidence in source identification accuracy, a one-way ANOVA was used. The independent variable was the type of feedback given to participants and the dependent variable was confidence in the accuracy of source identification. The analysis revealed that feedback had a significant impact on participant confidence in their source identification accuracy, $F(3,155)=3.90, p=.02$. Subsequent Tukey tests revealed that participants given confirming feedback were significantly more confident in the source identification accuracy compared to participants given disconfirming feedback $(p=.02)$. There were no other significant effects of feedback on source monitoring recall accuracy (see Table 8 for confidence ratings in source identification accuracy). 
Table 8

Confidence ratings in source monitoring accuracy $(1=$ not at all confidence and $7=$ extremely confident)

\begin{tabular}{lcccc}
\hline & \multicolumn{4}{c}{ Confidence Rating } \\
\hline \multirow{2}{*}{ Feedback Received } & $\mathrm{M}$ & $\mathrm{SD}$ & & \multicolumn{2}{c}{ Inaccurate } \\
Confirming & $5.67^{*}$ & 1.12 & $5.51^{*}$ & 1.21 \\
Neutral & 4.94 & 1.90 & 4.55 & 1.32 \\
None & 4.85 & 2.10 & 4.66 & 1.87 \\
Disconfirming & 4.04 & 1.51 & 4.30 & 2.00 \\
\hline
\end{tabular}

*Denotes significant difference at $p<.05$

Relationship between source identification accuracy and confidence. Next, a

Pearson correlation examined a possible relationship between source identification accuracy and confidence in source identification accuracy. There was no significant correlation between source identification accuracy and confidence in source identification accuracy, $r=0.19, n=158, p=.209$.

\section{Rapport Questionnaire}

To examine the effects of feedback (confirming vs. disconfirming vs. neutral vs. no feedback) on participants' perceptions of rapport with the interviewer, a one-way MANOVA was conducted and revealed a statistically significant effect of feedback on rapport, $F(63,347)=1.51, p=.012, \eta_{p}^{2}=.214$. Follow-up analyses revealed that feedback had a statistically significant effect on the perceived friendliness of the experimenter, $F(3,155)=3.34, p=.021, \eta_{p}^{2}=.069$. Specifically, post hoc Tukey tests demonstrated that participants given confirming feedback perceived the experimenter as being significantly more friendly compared to participants who participants given disconfirming feedback $(p=.036)$ and participants who received neutral feedback perceived the experimenter as being significantly more friendly compared to participants 
given disconfirming feedback $(p=.045)$. There were no other significant effects of feedback on perceptions of experimenter friendliness.

Feedback also had a statistically significant effect on the perceived positivity of the experimenter, $F(3,155)=2.87, p=.039, \eta_{\mathrm{p}}^{2}=.060$. A post hoc Tukey analysis revealed that participants given confirming feedback perceived the experimenter to be significantly more positive compared to participants given disconfirming feedback ( $p=$ .024). There were no other statistically significant effects of feedback on how positive participants perceived the experimenter to be.

Further analyses revealed that feedback had a statistically significant effect on how boring participants perceived the experimenter to be, $F(3,155)=3.49, p=.017, \eta_{p}^{2}$ $=.072$. Post hoc Tukey analyses showed that participants given confirming feedback perceived the experimenter to be significantly less boring compared to participants given disconfirming feedback ( $p=.016$ ). There were no other statistically significant effects of feedback on how boring participants perceived the experimenter to be.

Feedback also had a significant effect on how cold participants perceived the experimenter to be, $F(3,155)=3.13, p=.028, \eta_{\mathrm{p}}^{2}=.065$. A post hoc Tukey test revealed that participants given confirming feedback perceived the experimenter to be significantly less cold compared to participants given disconfirming feedback $(p=.021)$. There were no other statistically significant effects of feedback on how cold participants perceived the experimenter to be.

Further, feedback had a statistically significant effect on how awkward participants perceived the experimenter to be, $F(3,155)=5.22, p=.002, \eta_{p}^{2}=.103$. Follow up Tukey tests revealed that participants given confirming feedback perceived the 
experimenter to be significantly less awkward compared to participants given disconfirming feedback $(p=.001)$ and participants given no feedback perceived the experimenter to be significantly less awkward compared to participants given disconfirming feedback $(p=.028)$. There were no other statistically significant effects of feedback on how awkward participants perceived the experimenter to be (see Table 9 for rapport interaction ratings of interviewer by feedback condition).

Table 9

Rapport interaction ratings of interviewer by feedback condition

\begin{tabular}{|c|c|c|c|c|c|c|c|c|}
\hline & \multicolumn{8}{|c|}{ Feedback Received } \\
\hline & \multicolumn{2}{|c|}{ Confirming } & \multicolumn{2}{|c|}{ Neutral } & \multicolumn{2}{|c|}{ None } & \multicolumn{2}{|c|}{ Disconfirming } \\
\hline & M & SD & M & SD & M & SD & M & SD \\
\hline Smooth & 5.93 & 1.17 & 6.22 & 0.92 & 5.90 & 0.87 & 6.03 & 1.04 \\
\hline Satisfied & 5.77 & 1.34 & 5.49 & 1.45 & 5.42 & 1.09 & 5.07 & 1.46 \\
\hline Engaged & 6.25 & 0.94 & 6.08 & 1.21 & 6.10 & 1.01 & 5.86 & 1.04 \\
\hline Involved & 6.09 & 1.20 & 6.05 & 1.17 & 6.06 & 1.12 & 6.00 & 1.02 \\
\hline Friendly & $6.59 *$ & 0.82 & $6.59^{*}$ & 1.09 & 6.16 & 1.34 & 5.82 & 1.49 \\
\hline Active & 6.23 & 1.27 & 6.00 & 1.27 & 5.84 & 1.32 & 6.14 & 0.93 \\
\hline Positive & $6.39 *$ & 1.04 & 6.19 & 1.27 & 6.06 & 1.09 & 5.54 & 1.53 \\
\hline Likable & 6.59 & 0.82 & 6.30 & 1.15 & 6.16 & 0.97 & 5.96 & 1.07 \\
\hline Trustworthy & 5.86 & 1.61 & 6.11 & 1.26 & 5.97 & 1.17 & 5.57 & 1.26 \\
\hline Credible & 6.02 & 1.25 & 6.08 & 0.92 & 6.03 & 1.08 & 5.50 & 1.55 \\
\hline Boring & $1.36^{*}$ & 0.69 & 1.97 & 1.46 & 1.68 & 1.11 & 2.25 & 1.58 \\
\hline Cooperative & 6.34 & 1.01 & 6.11 & 1.22 & 6.10 & 1.00 & 5.79 & 1.60 \\
\hline Harmonious & 5.86 & 1.52 & 6.05 & 1.00 & 5.68 & 1.05 & 5.46 & 1.43 \\
\hline Unsatisfying & 4.73 & 2.39 & 4.46 & 2.41 & 5.26 & 1.71 & 4.46 & 2.01 \\
\hline Cold & $1.34 *$ & 0.96 & 1.70 & 1.39 & 1.94 & 1.29 & 2.25 & 1.55 \\
\hline Awkward & 1.36 & 0.75 & 1.68 & 1.00 & 1.58 & 1.03 & 2.36 & 1.50 \\
\hline Engaging & $6.16^{*}$ & 1.10 & 6.14 & 0.95 & $6.03 *$ & 1.02 & 5.68 & 1.19 \\
\hline Unfocused & 4.93 & 2.51 & 4.68 & 2.45 & 5.10 & 2.20 & 5.21 & 2.08 \\
\hline Involving & 6.16 & 1.24 & 6.11 & 0.91 & 5.94 & 1.34 & 5.64 & 1.28 \\
\hline
\end{tabular}

*Denotes significant effect at $\mathrm{p}<.05$

\section{Cognitive Load}

A one-way MANOVA examined the effects of feedback (confirming vs.

disconfirming vs. neutral vs. no feedback) on participants' perceptions of cognitive load. 
Specifically, how much participants felt they were being evaluated by the experimenter, how thoroughly participants were able to search through their memory, how much participants were thinking about other things throughout the course of the study, the level of mental effort expended during recall, and how difficult it was for participants to thoroughly search their memory during recall. A MANOVA revealed a statistically significant overall effect of feedback, $F(3,155)=2.59, p<.001, \eta_{p}^{2}=.084$.

Follow-up analyses revealed that feedback had a statistically significant effect on how thoroughly participants thought they were able to search through their memory, $F(3$, $155)=7.25, p<.001, \eta_{\mathrm{p}}^{2}=.131$. Post hoc Tukey tests showed that participants given confirming feedback reported being significantly better able to search their memory compared to participants given disconfirming feedback $(p<.001)$. There were no other statistically significant effects of feedback on how thoroughly participants reported being able to search through their memory.

Further analyses revealed a statistically significant effect of feedback on and how difficult it was for participants to search their memory, $F(3,155)=8.57, p<.001, \eta^{2}=$ .152. Follow up Tukey tests revealed that participants given confirming feedback reported significantly less difficulty searching their memory compared to participants given neutral feedback $(p=.033)$, participants given no feedback $(p=.017)$, and participants given disconfirming feedback, $(p<.001)$. There were no other statistically significant effects of feedback on how difficult it reportedly was for participants to search their memory. Lastly, there were no other statistically significant effects of feedback on measures of reported cognitive load (see Table 10 for mean ratings for measures of perceived cognitive load). 
Table 10

Mean ratings for measures of perceived cognitive load

\begin{tabular}{|c|c|c|c|}
\hline $\begin{array}{c}\text { Cognitive Load } \\
\text { Evaluation }\end{array}$ & Feedback Received & Mean & $\mathrm{SD}$ \\
\hline \multirow{4}{*}{$\begin{array}{l}\text { Interviewer } \\
\text { Evaluating You }\end{array}$} & Confirming & 4.40 & 1.67 \\
\hline & Neutral & 4.51 & 1.95 \\
\hline & None & 4.48 & 1.85 \\
\hline & Disconfirming & 5.00 & 2.16 \\
\hline \multirow{4}{*}{$\begin{array}{l}\text { Thorough Search } \\
\text { of Memory }\end{array}$} & Confirming & $5.73 *$ & 0.89 \\
\hline & Neutral & 5.14 & 0.98 \\
\hline & None & 5.23 & 1.17 \\
\hline & Disconfirming & 4.55 & 1.39 \\
\hline \multirow{4}{*}{$\begin{array}{l}\text { Thinking About } \\
\text { Other Things }\end{array}$} & Confirming & 2.93 & 1.86 \\
\hline & Neutral & 2.89 & 1.74 \\
\hline & None & 2.80 & 1.49 \\
\hline & Disconfirming & 2.89 & 1.73 \\
\hline \multirow{4}{*}{$\begin{array}{l}\text { Mental Effort } \\
\text { Expended }\end{array}$} & Confirming & 5.31 & 1.52 \\
\hline & Neutral & 5.84 & 0.93 \\
\hline & None & 5.14 & 1.46 \\
\hline & Disconfirming & 5.39 & 1.26 \\
\hline \multirow{4}{*}{$\begin{array}{l}\text { Difficulty } \\
\text { Searching Memory }\end{array}$} & Confirming & $3.16^{*}$ & 1.45 \\
\hline & Neutral & 4.08 & 1.48 \\
\hline & None & 4.17 & 1.60 \\
\hline & Disconfirming & 4.90 & 1.54 \\
\hline
\end{tabular}

*Denotes significant effect at $p<.05$

\section{Participant Suspicion}

Examining participant suspicion, a series of descriptive analyses revealed that one participant correctly identified the purpose of the study, 55 participants $(34.8 \%)$ believed the experimenter watched the video before the study, 59 participants $(37.3 \%)$ generally believed that there was deception involved in the study, and 58 participants $(36.7 \%)$ did not believe the experimenter when s/he said the video camera malfunctioned. 
To examine the impact of participant suspicion, all previously described analyses were run again after eliminating suspicious participants. There were no differences in results between analyses with or without suspicious participants. In other words, participant suspicion did not alter participants' response patterns as a function of feedback or question type.

\section{Experimenter Effects and Version Effects}

There were three experimenters who collected data throughout the course of the current study. When the variable of the experimenter was added as a covariate in the primary analyses for Interview 1, there was no significant effect of experimenter on witness accuracy, $F(2,156)=0.79, p=.287, \eta_{\mathrm{p}}^{2}=.024$, or quantity $F(2,156)=1.83, p=$ $.310, \eta_{\mathrm{p}}^{2}=.030$, and the main pattern of the results did not differ as a function of the experimenter. Furthermore, when the variable of experimenter was added as a covariate in the primary analyses for Interview 2, there was no significant effect of experimenter on witness accuracy, $F(2,156)=0.80, p=.092, \eta_{\mathrm{p}}^{2}=.002$, or quantity, $F(2,156)=1.42, p=$ $.098, \eta_{\mathrm{p}}^{2}=.022$, and the main trends in results did not differ as a function of the experimenter.

There were three version of the interview question order and three versions of the source monitoring questionnaire order, all containing the same questions but in different, randomized orders. When interview question order was added as a covariate in the primary analysis for Interview 1, there was no significant effect of question order on witness accuracy, $F(2,156)=0.89, p=.201, \eta_{\mathrm{p}}^{2}=.003$, or quantity, $F(2,156)=1.90, p=$ $.143, \eta_{\mathrm{p}}^{2}=.008$. Further, when interview question order was added as a covariate in the primary analysis for Interview 2, there again was no significant effect of question order 
on witness accuracy, $F(2,156)=0.71, p=.230, \eta^{2}=.001$, or quantity, $F(2,156)=0.58$, $p=.123, \eta_{\mathrm{p}}^{2}=.000$. Lastly, when the variable of question order was added as a covariate in the primary analysis for source monitoring, there was no significant effect of question order on source monitoring accuracy, $F(2,156)=0.18, p=.301, \eta_{p}^{2}=.008$, or confidence, $F(2,156)=1.00, p=.909, \eta^{2}{ }_{p}=.012$, and the main pattern of results did not differ as a result of question order. 


\section{DISCUSSION}

The current study sought to advance our understanding of the effects of postrecall feedback and question type on eyewitness recall and self-reports of confidence. Post-identification feedback has received a plethora of research and some policy attention over the past decade, but the effects of post-recall feedback have been largely neglected despite the fact that witnesses and victims are arguably interviewed repeatedly during any given investigation. To address this gap in the literature, the current study had four main goals.

The first goal was to examine potential effect(s) of different types of feedback, namely confirming, disconfirming, neutral, or no post-recall feedback, on subsequent eyewitness recall, confidence, and reports of view of the crime. Examining the impact of feedback was accomplished by asking participants to view a mock crime video, conducting an interview including open-ended and cued questions, giving participants either confirming, neutral, no, or disconfirming feedback about their recalled information, gathering self-reported confidence and reports of view of the perpetrator, conducting a second interview, and reassessing confidence and reports of view of the perpetrator.

Results revealed no impact of post-recall feedback on recall quantity or accuracy. That is, during Interview 2, participant recall did not differ as a function of the type of feedback that was given. The lack of a predicted effect may have been due to feedback's selective effect of metacognition and not episodic memory. That is, receiving information about the quality of one's prior recall may not alter a subsequent retrieval attempt but the retrospective assessment of a prior attempt only. 
Results also revealed that participants who received confirming feedback were significantly more confident compared to participants given neutral and no feedback and those who had disconfirming feedback had significantly lower confidence compared to those who received confirming, neutral, or no feedback. Further, disconfirming feedback appeared to lower mock witness confidence compared to those participants who were given neutral and no feedback.

The detrimental effect of disconfirming feedback on confidence is especially noteworthy given the SCIF's prediction that disconfirming feedback should not have a detrimental effect on confidence given that witnesses are predicted to disregard external cues that are not confirming (Charman et al., 2010). In contrast to the prediction of the SCIF, the data in the current study suggest that at least in witness recall settings, disconfirming feedback may lead to a substantial decrease in confidence compared to no or neutral feedback.

Although the SCIF suggests that witnesses disregard non-confirming cues, some research on post-identification feedback does suggest that disconfirming feedback can negatively affect witness confidence (Douglas \& Steblay, 2006; Steblay et al., 2014; Wells \& Bradfield, 1998), even if disconfirming feedback is less impactful than the effects of confirming feedback on identification confidence (Douglas \& Steblay, 2006). One possible explanation for the substantial impact of disconfirming post-recall feedback on participant confidence in the current study may be the result of one major difference between a lineup identification and recalling a critical event via an investigative interview: the number of informational units offered. 
During a lineup identification, witnesses are generally only offering the identity of who they believe to be the perpetrator. However, during the recall of a critical event, participants are likely offering a plethora of informational units (e.g., details about the perpetrator, other witnesses, the setting, etc.). It is thus possible that providing witnesses with disconfirming feedback about the overall accuracy of an entire recall led to a generalization of said feedback across all informational unit and, in turn, substantially reduced confidence in overall recall. Further, as Wells and Bradford (1998) note, the impact of post-identification feedback will likely differ greatly depending upon the way in which that feedback is operationalized. As such, it may have been the general way in which feedback was offered in this study (“Although I haven't watched the video, I've been given information about the video from the experimenters in charge of the study and the information you've given me seems to be inaccurate.") that impacted participant confidence.

As to whether the relationship between confidence and accuracy was moderated by feedback, the data show no correlation between confidence and accuracy in any feedback condition. That is, the first and second assessments of participant confidence and perception of recall accuracy were neither related to the actual accuracy of recall for Interview 1 nor for Interview 2, respectively. The finding of no significant correlation between confidence and accuracy is in line with previous eyewitness identification research which suggests that confidence in a lineup selection is not always a reliable predictor of accuracy (Brewer, Keast, \& Rishworth, 2002). However, given the potentially intricate relationship between confidence and accuracy (Sporer et al., 1995), future research will be needed to examine whether the relationship between confidence 
and accuracy may be moderated by the type of task participants are asked to perform (e.g., recall vs. identification).

The second goal of the current study was to examine the effects of different types of feedback on witnesses' subsequent suggestibility to misinformation. Recall that participants were asked suggestive questions after they had been given feedback. Contrary to predictions, participants' vulnerability to suggestion did not vary as a function of feedback.

There are a variety of ways to test for witness suggestibility in experimental paradigms, such as the misinformation paradigm, suggestive questions or the DRM paradigm (Pezdek \& Lam, 2007). As such, the size and nature of a suggestibility effect in various settings can depend on the way it is operationalized. In the present study, we tested for witness suggestibility using suggestive questions, half of which were correct, others incorrect. Whereas the post-recall feedback was of a general nature, each suggestive question targeted one specific to-be-remembered item. It is thus possible that general feedback does not affect subsequent vulnerability to suggestion for specific details.

The third goal was to examine possible interactions between post-recall feedback and question format on witness recall, confidence, and reports of view of a crime. As predicted, open-ended questions elicited a higher quantity and accuracy of information compared to cued questions during both Interview 1 and Interview 2 . The finding that open-ended interview questions are more beneficial compared to cued questions is consistent with a long line of research findings documenting and encouraging the use of free narratives via suggesting that open-ended questions allow participants to carefully 
monitor their own knowledge and determine their own output criteria (Fisher \& Geiselman, 1992; Koriat \& Goldsmith, 1996; Powell, Fisher, \& Wright, 2005).

The final goal of the current research was to assess the impact of feedback on the accuracy of witness source monitoring. Data revealed that the type of feedback given to witnesses did not significantly affect subsequent source monitoring abilities. Past research has documented that source monitoring processes can be impaired via a variety of external factors (e.g., Johnson et al., 1993; Johnson et al., 1995). However, in the current study, feedback did not appear to affect mechanisms that bolster or enhance source monitoring abilities.

An important piece to the puzzle of post-recall feedback was provided by the finding that those participants who were given confirming feedback rated the interviewer higher on measures of rapport compared to participants given neutral, no, and disconfirming feedback. Specifically, participants given confirming feedback perceived the experimenter as being significantly more friendly and positive compared to participants given disconfirming feedback. Further, participants given neutral feedback also perceived the experimenter as being significantly friendlier compared to participants given disconfirming feedback. Some research has found rapport to be beneficial to participant recall (Collins et al., 2002; Kieckhaefer et al., 2014; Vallano \& Schreiber Compo, 2011).

To the extent that disconfirming feedback is perceived as negative interviewing behavior and interviewer rapport, it may thus affect witnesses' post hoc metacognitive assessment of their prior recall - that is, their confidence in the previously provided statement. However, considering that there was no impact of feedback on accuracy or 
quantity of information recalled, feedback may only have an indirect effect on interviewer rapport. Rather, participants may have simply perceived experimenters giving confirming feedback as generally being more friendly and positive because they validated their memory skills and/or effort, while they viewed experimenters giving disconfirming feedback as being cold and awkward for doing the opposite.

Lastly, findings of perceived cognitive load were affected by the type of feedback given to participants. Participants given confirming feedback tended to perceive their cognitive load as being significantly lower compared to participants given disconfirming feedback. Specifically, participants who received confirming feedback reported being significantly more able to thoroughly search their memory compared to participants who received disconfirming feedback. Further, participants who received confirming feedback reported having significantly less difficulty searching through their memory compared to participants given neutral, no, and disconfirming feedback.

It is important to point out however, that there was no direct impact of feedback on witness recall quantity or accuracy suggesting that the effect of feedback on cognitive load was limited at best. Further, the current study asked participants about perceived cognitive load rather than using an objective measure of cognitive load (e.g., by having participants complete a secondary, cognitively demanding task). Also, as people are largely unable to accurately assess their underlying and non-conscious cognitive processes (Nisbett \& Wilson, 1977; Wilson, 2002), asking participants about their perception of cognitive load may not have been an accurate measure of cognitive load. As such, it may have been that because participants given confirming feedback were told their recall was accurate, they concluded that they must have been able to search through 
their memory, whereas participants given disconfirming feedback may have concluded they must not have been able to thoroughly search their memory.

\section{Practical and Theoretical Implications}

The current research aimed at developing a better understanding of whether the impact of post-recall feedback parallels findings for the effects of post-identification feedback on witness confidence. It further examined the effects of feedback on a new outcome measure, namely repeated retrieval. In line with research on lineup identifications, data revealed that confirming feedback inflates subsequent witness confidence for prior recall, but not for the accuracy of subsequent recall. In contrast to predictions of the SCIF (Charman et al., 2010), the current research also showed that even disconfirming feedback can affect subsequent witness confidence. The present set of findings can help inform and possibly help modify the SCIF to account for the divergence between the current results and the outcome predicted by the SCIF.

Further, findings on the advantages of free recall directly support theories and policy recommendations of the use of such technique in enhancing witness recall. The present data equally support a long line of research on the advantages of repeated retrieval (Fisher \& Schreiber, 2007), namely, the opportunity to glean new pieces of information about the mock crime from participants after an exhaustive free-recall opportunity.

Data from the current research can inform law enforcement interviewers and the legal system of the consequences of offering post-recall feedback. Findings suggest that offering confirming feedback inflates subsequent witness confidence and offering disconfirming feedback can decrease subsequent witness confidence, but not necessarily 
accuracy. Thus, interviewers should monitor closely if and what type of feedback has been given to a witness after recall noting that no feedback should be given until an untainted measure of confidence can be obtained.

Furthermore, although rapport may only have been partially enhanced via feedback in the current study, research-based investigative interviewing guidelines encourage interviewers to utilize techniques which will facilitate future communication between witnesses and law enforcement practitioners (Fisher \& Geiselman, 1992; Technical Working Group for Eyewitness Evidence, 1999; 2003). The current research suggests that even participants given neutral feedback, which did not inflate confidence compared to those given confirming feedback, rated the experimenter as being more friendly compared to participants given disconfirming feedback. Taken together, it may be that law enforcement practitioners can use neutral feedback to help build rapport which may lead to enhanced communication between witnesses and law enforcement interviewers.

As a result of the combination of an ecologically valid design with strong experimental control, these results may be particularly impactful at the interface of research and investigative interviewing practice with the long-term goal of putting forward policy recommendations. Because witness confidence and accuracy are two of the most crucial factors jurors use to assess credibility, it is important for legal psychology researchers and law enforcement and legal professionals to take into consideration possible effects of post-identification feedback on subsequent witness measures. As such, the results can help "bridge the gap" between laboratory researchers and the law enforcement community as well as legal professionals such as judges and 
attorneys, especially given that feedback and question type are both system variables and, as such, under the control of the legal system.

\section{Limitations}

The current study had several limitations. One limitation was the use of a crime video rather than a live crime. Given the ethical constraints, the current study did not place participants in a situation where they perceived their physical safety to be in jeopardy (e.g., through the use of an in-person armed robbery). Although a live crime option would have been a casual or subtle robbery such as the taking of a laptop, these scenarios often leave the participant unaware that a crime is even taking place until they are informed by an experimenter or confederate associated with the study. Thus, despite the fact that the use of a crime video is unlikely to induce the same anxiety and/or stress that would come with a staged armed robbery, it arguably parallels similar memory and attentional processes. For these reasons, the use of crime videos has been widely accepted as an adequately parallel stimulus (Memon, Meissner, \& Fraser, 2010). The primary advantage of using a crime video is that presenting each participant with the exact same crime minimizes the likelihood that differences between participants are the result of variation of the target stimulus.

A second limitation in the current study was the form of the question asking about confidence. The form of the question in the current study ("On a scale of one to seven with one being extremely not confident and seven being extremely confident, how confident are you that the information you have given me in your statement is accurate?") asked about current confidence rather than confidence at the time of recall. Although participant confidence still appeared to be affected by the feedback manipulation, the 
form of the question may not have elicited a retrospective reflection of confidence. In other words, the question in its current form may not have prompted participants to assess their confidence at the time of recall and thus did not examine if feedback actually changed the memory of confidence at the time of recall. As such, the conclusion cannot be drawn from the current data that post-recall feedback distorts recall of how confident participants were at the time of recall.

A third potential issue with the current study is the composition of the sample. The sample in the present study was primarily female and Hispanic, with all of the participants enrolled in an undergraduate program at the time of participation. While gender and ethnicity would not be expected to interact with memory, recall, confidence, or source monitoring abilities, attendance at a university may indicate that participants in the current study may have differed from the general population in their cognitive and attentional skills. Future researcher should thus expand upon current findings with increasingly representative samples.

\section{Future Research}

The use of a live target event may help to provide stimulus generalization and investigate whether the findings in the current study hold true for participants witnessing a live crime. The use of a live crime would allow researchers to examine the potential impact of stress and anxiety of having witnessed a "real" crime. Being interviewed about a more authentic crime may also prompt participants to be more accurate or thorough in their recall of a target event. The viewing of a live crime may also make the results of such a study more representative of real-world procedures and generalizable for law enforcement practitioners. 
Interviewing participants about a more realistic target event would also give researchers the opportunity to examine different sources of information as the justification for giving feedback. For example, experimenters could tell participants that the information which allows them to give feedback (e.g., "The information you gave me appears to be accurate.") came from various sources such as security camera footage, other witness accounts, or the confession of a suspect. It may also be valuable to examine conflicting sources of feedback. For example, future researchers could present participants with information from one source (e.g., an investigator) suggesting the recall of the witness is accurate and compare it to the feedback from another, possibly less credible source. Future research would also be able to examine whether the present set of findings can be replicated. Considering that research on post-recall feedback is in its infancy, it will be critical to not only ensure the impact of post-recall feedback on confidence is reliable, but to understand the theoretical underpinnings of why post-recall feedback impacts confidence.

One topic that should be addressed specifically in future research is the divergence from what was predicted by the SCIF (Charman et al., 2010). As discussed above, the SCIF predicted that disconfirming feedback would have no impact on confidence. However, the current study showed that disconfirming feedback had a significantly deleterious effect on confidence. One possible explanation for the negative impact of disconfirming feedback on confidence is the number of units recalled during an investigative interview compared to the typically single unit of information that is given during a lineup. As such, future research should examine the potential impact of witnesses receiving feedback on single versus multiple pieces of information. 
Future research should also address any effect of generalized feedback, as was used in current study, versus more specific feedback on an individual piece of information given during recall. For example, offering feedback on the ethnicity of a perpetrator rather than on the entire recall of a participant. Offering disconfirming feedback on a single piece of information may yield somewhat counter-intuitive research: that disconfirming feedback may actually enhance participant confidence rather than diminish it. The reason that disconfirming feedback on a single piece of "incorrect" information may actually bolster participant confidence is that participants may believe that, if only a single piece of their recall (e.g., race of the perpetrator) was incorrect, the feedback on that specific piece may automatically imply that the rest of their recall was correct. Believing that only one incorrect detail out of many is incorrect may bolster confidence for the remaining pieces of information reported, rather than damaging it. Alternatively, disconfirming feedback on a single piece of information may decrease confidence if participants believe their inaccurate recall on a single piece of information is indicative of the accuracy of other units of information they recalled.

Another promising direction for future research is to examine the impact of postrecall feedback on the perception of witnesses who have received feedback. In other words, researchers could examine whether there are any differences in the way(s) in which witnesses who have been given various types of post-recall feedback are perceived by decision makers (i.e., jurors). Smalarz and Wells (2014) have examined the impact of post-identification feedback on perceptions of witnesses by neutral observers. Specifically, participants made either an accurate or inaccurate lineup identification and were then given either confirming feedback (e.g., "Good job! You identified the 
suspect.") or no feedback. These participants then gave videotaped testimony about the identification that they made. Next, a second group of participants (evaluators) were shown the subsequent testimony from members of the first group of participants with the goal of assessing the accuracy of the identification members of the first group made. Results revealed that evaluators who were shown video testimony of participants who were not given feedback rated participants who made an accurate identification as significantly more likely to be accurate compared to participants who were given confirming feedback. In other words, results demonstrated that post-identification feedback harms the ability of evaluators to correctly judge accurate and mistaken witness testimony.

As an extension of Smalarz and Wells (2014), future researchers should present independent evaluators post-feedback interviews to examine whether various types of feedback (e.g., confirming, neutral, disconfirming) has any impact on evaluator perceptions of believability, accuracy, confidence, and trustworthiness of participants after they have been given feedback. Researchers could then compare pre-feedback recall and post-feedback recall to explore any potential differences in credibility.

Lastly, a direction for future research would be to examine the combination of a lineup identification, post-recall and/or post-identification feedback, and at least one investigative interview. Research examining a combination of these factors would be especially important given that witnesses in real world investigations typically encounter a lineup identification, at least one investigative interview, and possibly investigator feedback throughout the course of an investigation. For example, researchers may examine the impact of post-recall feedback (confirming, neutral, none, or disconfirming) 
followed by a lineup after which post-identification feedback (confirming, neutral, none, or disconfirming) is given. It would be important to examine the effects of differing types of feedback throughout the course of an investigation as well as feedback on various aspects of information offered by witnesses (e.g., investigative interview recall versus lineup identification).

\section{Conclusion}

The number of wrongful conviction cases which involve suboptimal information collected from witnesses during lineup identifications or investigative interviews is troublesome. As such, it is important for researchers to continue to explore ways in which the quantity and accuracy of information offered by witnesses can be maximized. Further, it will be critical to assess the ways in which perceived indicators of credibility (i.e., confidence) can be knowingly or unknowingly altered by investigators and the ways in which the relationship between confidence and accuracy can be moderated so that reported confidence in accuracy can closely represent actual accuracy.

It will also be important for researchers to focus on the variety of ways in which the collection of a high quantity of accurate information from witnesses can be maximized throughout the course of a criminal investigation. Researchers should not only continue to explore and refine the understanding of investigative interviewing techniques that have already been established (e.g., best practice interviewing techniques), but investigate novel system variables which may impact the quantity and accuracy of information gathered by law enforcement practitioners. 


\section{REFERENCES}

Ayers, M. S., \& Reder, L. M. (1998). A theoretical review of the misinformation effect: Predictions from an activation-based memory model. Psychonomic Bulletin \& Review, 5(1), 1-21.

Baddeley, A. D. (1986). Working memory. Oxford: Oxford University Press.

Bain, S. A., \& Baxter, J. S. (2000). Interrogative suggestibility: The role of interviewer behaviour. Legal and Criminological Psychology, 5, 123-133.

Baxter, J. S., Charles, K. E., Martin, M., \& McGroarty, A. (2012). The relative influence of leading questions and negative feedback on response change on the Gudjonsson Suggestibility Scale (2): Implications for forensic interviewing. Psychology, Crime and Law, 18, 1-9.

Belli, R. F., \& Loftus, E. F. (1994). Recovered memories of childhood abuse: A source monitoring perspective. In S. J. Lynn \& J.W. Rhue (Eds), Dissociation: Clinical and Theoretical Perspectives, pp. 415-433. Guilford Press: New York.

Bem, D. J. (1967). Self-perception: An alternative interpretation of cognitive dissonance phenomena. Psychological Review, 74(3), 183-200.

Bem, D. J. (1972). Self-perception theory. In L. Berkowitz (Ed.), Advances in Experimental Social Psychology, (Vol. 6. pp 1-62). Academic Press, New York.

Blanton, H., Pelham, B. W., DeHart, T., \& Carvallo, M. (2001). Overconfidence as dissonance reduction. Journal of Experimental Social Psychology, 37, 373-385.

Bothwell, R. K., Deffenbacher, K. A., \& Brigham, J. C. (1987). Correlation of eyewitness accuracy and confidence: Optimality hypothesis revisited. Journal of Applied Psychology, 72, 691-695.

Bradfield, A. L., \& Wells, G. L. (2000). The perceived validity of eyewitness identification testimony: A test of the five Biggers criteria. Law and Human Behavior, 24(5), 581-594.

Bradfield, A. L., Wells, G. L., \& Olson, E. A. (2002). The damaging effect of confirming feedback on the relation between eyewitness certainty and identification accuracy. Journal of Applied Psychology, 87, 112-120.

Brewer, N., \& Burke, A. (2002). Effects of testimonial inconsistencies and eyewitness confidence on mock-juror judgments. Law and Human Behavior, 26(3), 353-364. 
Brewer, N., \& Wells, G. L. (2006). The confidence-accuracy relationship in eyewitness identification: Effects of lineup instructions, foil similarity, and target-absent base rates. Journal of Experimental Psychology: Applied, 12, 11-30.

Charman, S. D., Carlucci, M., Vallano, J., \& Gregory, A. H. (2010). The selective cue integration framework: A theory of postidentification witness confidence assessment. Journal of Experimental Psychology: Applied, 16(2), 204-218.

Collins, R., Lincoln, R., \& Frank, M. G. (2002). The effects of rapport in forensic interviewing. Psychiatry, Psychology \& Law, 91, 69-78.

Dent, H. R., \& Stephenson, G. M. (1979). An experimental study of the effectiveness of different techniques of questioning child witnesses. British Journal of Social and Clinical Psychology, 18, 41-51.

Douglass, A., \& Steblay, N., (2006). Memory distortion in eyewitnesses: A meta-analysis of the post-identification feedback effect. Applied Cognitive Psychology, 20, 859869.

Evans, J. R., \& Fisher, R. P. (2011). Eyewitness memory: Balancing the accuracy, precision and quantity of information through metacognitive monitoring and control. Applied Cognitive Psychology, 25(3), 501-508.

Faul, F., Erdfelder, E., Lang, A. G., \& Buchner, A. (2007). G*Power 3: A flexible statistical power analysis program for the social, behavioral, and biomedical sciences. Behavior Research Methods, 39, 175-191.

Fischhoff, B. (1977). Perceived informativeness of facts. Journal of Experimental Psychology: Human Perception \& Performance, 3, 349-358.

Fisher, R. P., \& Geiselman, R. E. (1992). Memory-enhancing techniques for investigative interviewing: The Cognitive Interview. Springfield, Illinois: Charles C. Thomas.

Fisher, R. P., Geiselman, R. E., \& Raymond, D. S. (1987). Critical analysis of police interviewing techniques. Journal of Police Science and Administration, 15, 177185.

Gudjonsson, G. H. (1984). A new scale of interrogative suggestibility. Personality and Individual Differences, 5, 303-314.

Gudjonsson, G. H. (1988). Interrogative suggestibility: Its relationship with assertiveness, social-evaluative anxiety, state anxiety and method of coping. British Journal of Clinical Psychology, 27, 159-166. 
Gudjonsson, G. H., \& Clark, N. K. (1986). Suggestibility in police interrogation: A social psychological model. Social Behaviour, 1(2), 83-104.

Hall, J. A., Roter, D. L., Blanch, D. C., Frankel, R. M., (2009). Observer-rated rapport in interactions between medical students and standardized patients. Education and Counseling, 76, 323-327.

Hammond, L., Wagstaff, G. F., \& Cole, J. (2006). Facilitating eyewitness memory in adults and children with context reinstatement and focused meditation. Journal of Investigative Psychology and Offender Profiling, 3(2), 117-130.

Hastie, R., \& Park, B. (1986). The relationship between memory and judgment depends on whether the judgment task is memory-based or on-line. Psychological Review, 93, 258-268.

Henry, L. A., \& Gudjonsson, G. H. (1999). Eyewitness memory and suggestibility in children with mental retardation. American Journal on Mental Retardation, 104(6), 491-508.

Home Office (2002). Achieving best evidence in criminal proceedings: Guidance on vulnerable or intimidated witnesses including children. London: Home Office.

Innocence Project. (n.d.). Retrieved from the Innocence Project: Know the cases: http://www.innocenceproject.org/understand/Eyewitness-Misidentification.php.

Johnson, M. K., Bush, J. G., \& Mitchell, K. J. (1998). Interpersonal reality monitoring: Judging the sources of other people's memories. Social Cognition, 16(2), 199-224.

Johnson, M. K., De Leonardis, D. M., Hashtroudi, S., \& Ferguson, S. A. (1995). Aging and single versus multiple cues in source monitoring. Psychology and Aging, 10(4), 507-517.

Johnson, M. K., Hashtroudi, S., \& Lindsay, D. S. (1993). Source monitoring. Psychological Bulletin, 114(1), 3-28.

Kahneman, D. (1970). Remarks on attention control. Acta Psychologica, 33, 118-131.

Kahneman, D. (1973). Attention and effort. Englewood Cliffs, NJ: Prentice-Hall.

Karpel, M. E., Hoyer, W. J., \& Toglia, M. P. (2001). Accuracy and qualities of real and suggested memories: Nonspecific age differences. Journal of Gerontology: Series B: Psychological Sciences and Social Sciences, 56B, 103-110. 
Kebbell, M. R., \& Milne, R. (1998). Police officers' perceptions of eyewitness performance in forensic investigations. The Journal of Social Psychology, 138(3), 323-330.

Kieckhaefer, J. M. (2014). Understanding rapport-building in investigative interviews: Does rapport's effect on witness memory and suggestibility depend on the interviewer? (Unpublished doctoral dissertation). Florida International University, Miami, FL.

Kieckhaefer, J., Schreiber Compo, N. \& Vallano, J. P. (2014). Examining the positive effects of rapport building: When and why does rapport building benefit adult eyewitness memory? Memory, 20(8), 1010-1023.

Koriat, A., \& Goldsmith, M. (1996). Monitoring and control processes in the strategic regulation of memory accuracy. Psychological Review, 103(3), 490-517.

Laird, J. D. (1974). Self-attribution of emotion: The effects of expressive behavior on the quality of emotional experience. Journal of Personality And Social Psychology, 29(4), 475-486.

Lindsay, D. S. (1990). Misleading suggestions can impair eyewitnesses' ability to remember event details. Journal of Experimental Psychology: Learning, Memory, and Cognition, 16(6), 1077-1083.

Lindsay, D., \& Johnson, M. K. (1989). The eyewitness suggestibility effect and memory for source. Memory \& Cognition, 17(3), 349-358.

Lindsay, D. S., Read, J. D., \& Sharma, K. (1998). Accuracy and confidence in person identification: The relationship is strong when witnessing conditions vary widely. Psychological Science, 9, 215-218.

Loftus, E. F. (1975). Leading questions and the eyewitness report. Cognitive Psychology, 7, 560-572.

Loftus, E. F., Miller, D. G., Burns, H. J. (1978). Semantic integration of verbal information into visual memory. Journal of Experimental Psychology: Human Learning and Memory, 4, 19-31.

Loftus, E. F. \& Palmer, J. C. (1974). Reconstruction of automobile destruction: An example of the interaction between language and memory. Journal of Verbal Learning and Verbal Behavior, 13, 585-589.

Loftus, E. F., \& Zanni, G. (1975). Eyewitness testimony: The influence of the wording of a question. Bulletin of the Psychonomic Society, 5(1), 86-88. 
Lord, C. G., Ross, L., \& Lepper, M. R. (1979). Biased assimilation and attitude polarization: The effects of prior theories on subsequently considered evidence. Journal of Personality and Social Psychology, 37, 2098-2109.

McCloskey, M., \& Zaragoza, M. (1985). Misleading postevent information and memory for events: Arguments against memory impairment hypotheses. Journal of Experimental Psychology: General, 114, 1-16.

McMurtrie, H., Baxter, J. S., Obonsawin, M. C., \& Hunter, S. C. (2012a). Consistent witness responses: The effects of age and negative feedback. Personality and Individual Differences, 53(8), 958-962.

McMurtrie, H., Baxter, J. S., Obonsawin, M. C., \& Hunter, S. C. (2012b). The relationship between memory beliefs, compliance and response change within a simulated forensic interview. Personality and Individual Differences, 52(5), 591595.

Memon, A. (2009). Modifying the Cognitive Interview for suspect interviews [PowerPoint slides]. Retrieved from Scottish Institute for Policing Research website: www.sipr.ac.uk/downloads/Deception/Memon.pps.

Memon, A., Meissner, C. A., \& Fraser, J. (2010). The Cognitive Interview: A metaanalytic review and study space analysis of the past 25 years. Psychology, Public Policy, and Law, 16(4), 340-372.

Memon, A., \& Vartoukian, R. (1996). The effects of repeated questioning on young children's eyewitness testimony. British Journal of Psychology, 87(3), 403-415.

Miles, K. L., Powell, M. B., Gignac, G. E., \& Thomson, D. M. (2007). How well does the Gudjonsson suggestibility scale for children, Version 2 predict the recall of false details among children with and without intellectual disabilities? Legal and Criminological Psychology, 12(2), 217-232.

Mitchell, K. J., \& Johnson, M. K. (2000). Source monitoring: attributing mental experiences. In E. Tulving \& F. I. M. Craik (Eds), The Oxford Handbook of Memory, pp. 179-195. Oxford University Press: New York.

Mitchell, K. J., Johnson, M. K., \& Mather, M. (2003). Source monitoring and suggestibility to misinformation: Adult age-related differences. Applied Cognitive Psychology, 17, 107-119.

Neuschatz, J. S., Preston, E. L., Burkett, A. D., Toglia, M. P., Lampinen, J. M., Neuschatz, J. S., Fairless, A. H., Lawson, D. S., Powers, R. A., \& Goodsell, C. A. (2005). The effects of post-identification feedback and age on retrospective eyewitness memory. Applied Cognitive Psychology, 19(4), 435-453. 
Neuschatz, J. S., Lawson, D. S., Fairless, A. H., Powers, R., Neuschatz, J. S., Goodsell, C. A., \& Toglia, M. P. (2007). The mitigating effects of suspicion on postidentification feedback and on retrospective eyewitness memory. Law and Human Behavior, 31(3), 231-247.

Newberry, J. J., \& Stubbs, C. A. (1990). Advanced Interviewing Techniques. Glynco, Georgia: Bureau of Alcohol, Tobacco, and Firearms National Academy.

Nisbett, R. E., \& Wilson, T. D. (1977). Telling more than we can know: Verbal reports on mental processes. Psychological Review, 84(3), 231-259.

Orbach, Y., Hershkowitz, I., Lamb, M. E., Sternberg, K. J., Esplin, P. W., \& Horowitz, D. (2000). Assessing the value of structured protocols for forensic interviews of alleged child abuse victims. Child Abuse and Neglect, 24, 733-752.

Petty, R. E., Cacioppo, J. T., \& Goldman, R. (1981). Personal involvement as a determinant of argument-based persuasion. Journal of Personality and Social Psychology, 41(5), 847-855.

Pezdek, K. \& Lam, S. (2007). What research paradigms have cognitive psychologists used to study "false memory," and what are the implications of these choices? Consciousness \& Cognition, 16, 2-17.

Pirmoradi, M., \& McKelvie, S. (2014). Feedback, confidence, and false recall in the DRMRS procedure. Current Psychology: A Journal for Diverse Perspectives on Diverse Psychological Issues. Advance online publication.

Powell, M. B., Fisher, R. P., \& Wright, R. (2005). Investigative Interviewing. In N. Brewer \& K. D. Williams (Eds.), Psychology and law: An empirical perspective (pp. 11-42). New York, NY: Guilford Press.

Powell, M. B., \& Thomson, D. M. (1996). Children's memory of an occurrence of a repeated event: Effects of age, repetition, and retention interval across three question types. Child Development, 67, 1988-2004.

Scheck, B., Neufeld, P., \& Dwyer, J. (2000). Actual Innocence. New York: Doubleday.

Schreiber Compo, N., Hyman Gregory, A., \& Fisher, R. (2012). Interviewing behaviors in police investigators: A field study of a current US sample. Psychology, Crime \& Law, 18(4), 359-375.

Sporer, S., Penrod, S., Read, D., \& Cutler, B. L. (1995). Choosing, confidence, and accuracy: A meta-analysis of the confidence-accuracy relation in eyewitness identification studies. Psychological Bulletin, 118, 315-327. 
Steblay, N. M. (1992). A meta-analytic review of the weapon focus effect. Law and Human Behavior, 16(4), 413-424.

Steblay, N. M. (1997). Social influence in eyewitness recall: A meta-analytic review of lineup instruction effects. Law and Human Behavior, 21(3), 283-297.

Steblay, N. K., Wells, G. L., \& Douglass, A. B. (2014). The eyewitness post identification feedback effect 15 years later: Theoretical and policy implications. Psychology, Public Policy, and Law, 20(1), 1-18.

Strack, F., Martin, L. L., \& Stepper, S. (1988). Inhibiting and facilitating conditions of the human smile: A nonobtrusive test of the facial feedback hypothesis. Journal of Personality and Social Psychology, 54(5), 768-777.

Technical Working Group for Eyewitness Evidence. (1999). Eyewitness evidence: A guide for law enforcement. U.S. Department of Justice, Office of Justice Programs, National Institute of Justice.

Technical Working Group for Eyewitness Evidence. (2003). Eyewitness evidence: A guide for law enforcement. Trainer's Manual. U.S. Department of Justice, Office of Justice Programs, National Institute of Justice.

Tulving, E. (1983). Elements of episodic memory. Oxford, England: Clarendon Press.

Vallano, J. P., \& Schreiber Compo, N. (2011). A comfortable witness is a good witness: Rapport-building and susceptibility to misinformation in an investigative mockcrime interview. Applied Cognitive Psychology, 25(6), 960-970.

Vallano, J. P., \& Schreiber Compo, N. (2015). Rapport-building with cooperative witnesses and criminal suspects: A theoretical and empirical review. Psychology, Public Policy, and the Law, 21(1), 85-99.

Weber, N., \& Brewer, N. (2003). The effect of judgment type and confidence scale on confidence-accuracy calibration in face recognition. Journal of Applied Psychology, 88, 490-499.

Wells, G. L. (1978). Applied eyewitness-testimony research: System variables and estimator variables. Journal of Personality and Social Psychology, 36(12), 15461557.

Wells, G. L., \& Bradfield, A. L. (1998). "Good, you identified the suspect": Feedback to eyewitnesses distorts their reports of the witnessing experience. Journal of Applied Psychology, 83(3), 360-376. 
Wells, G. L., \& Bradfield, A. L. (1999). Distortions in eyewitnesses' recollections: Can the postidentification-feedback effect be moderated? Psychological Science, 10(2), 138-144.

Wells, G. L., Ferguson, T. J., \& Lindsay, R. C. L. (1981). The tractability of eyewitness confidence and its implication for triers of fact. Journal of Applied Psychology, $66,688-696$.

Wells, G. L., Memon, A., \& Penrod, S. D. (2006). Eyewitness evidence: Improving its probative value. Psychological Science in the Public Interest, 7(2), 45-75.

Wells, G. L., \& Murray, D. M. (1984). Eyewitness confidence. In G. L. Wells \& E. F. Loftus (Eds.), Eyewitness testimony: Psychological perspectives (pp. 155-170). New York: Cambridge University Press.

Wells, G. L., Small, M., Penrod, S., Malpass, R. S., Fulero, S. M., \& Brimacombe, C. A. E. (1998). Eyewitness identification procedures: Recommendations for lineups and photospreads. Law and Human Behavior, 22(6), 603-647.

Wilson, T. D. (2002). Strangers to ourselves: Discovering the adaptive unconscious. Cambridge, M.A.: Harvard University Press. 
Appendix A

The selective cue integration framework*

$\underline{\text { Stage }}$

$\underline{\text { Cognitive process }}$

Outcome

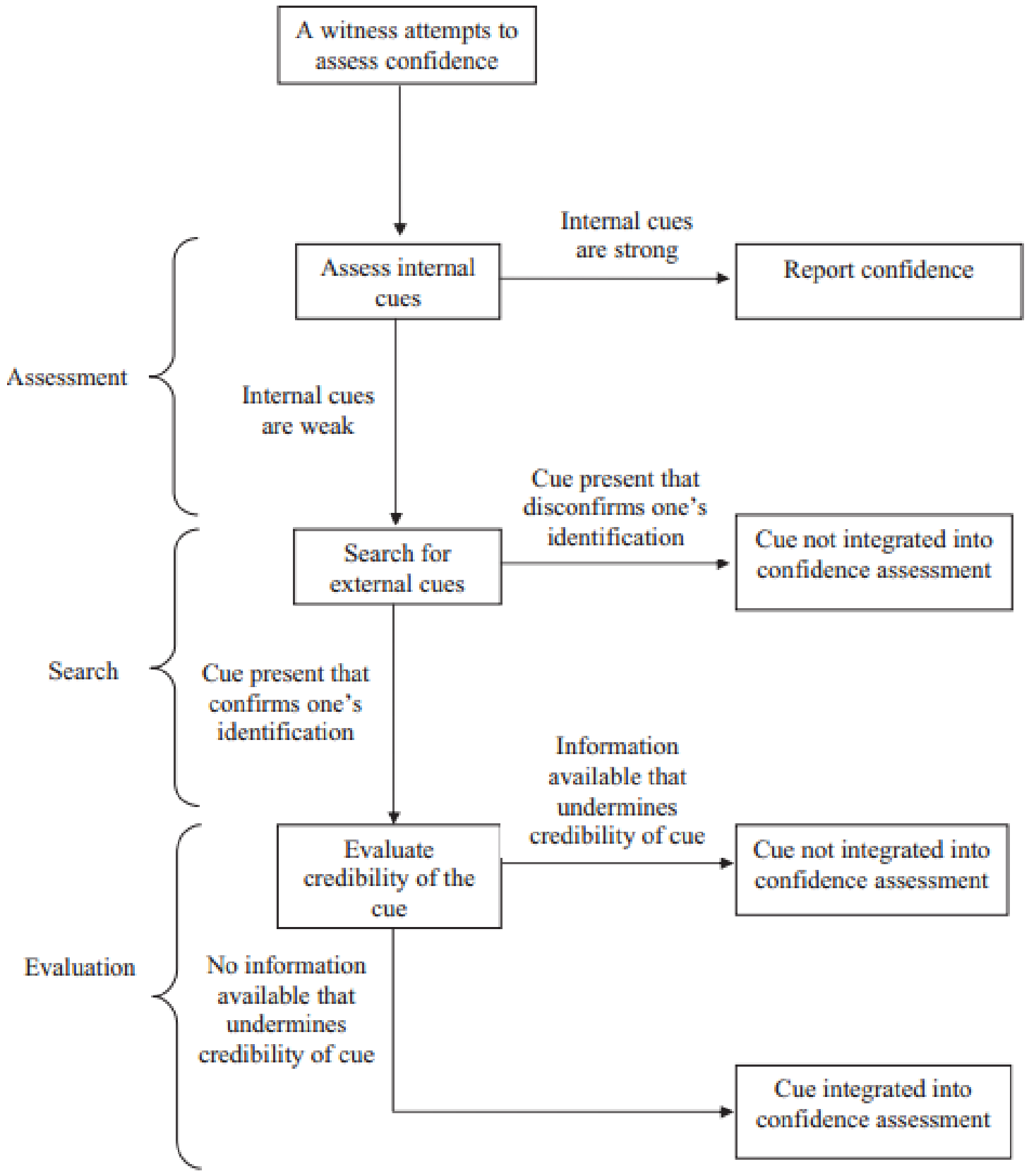

*Diagram from Charman, Carlucci, Vallano, \& Hyman Gregory (2010), p. 206 
Appendix B

Still shot of mock crime video

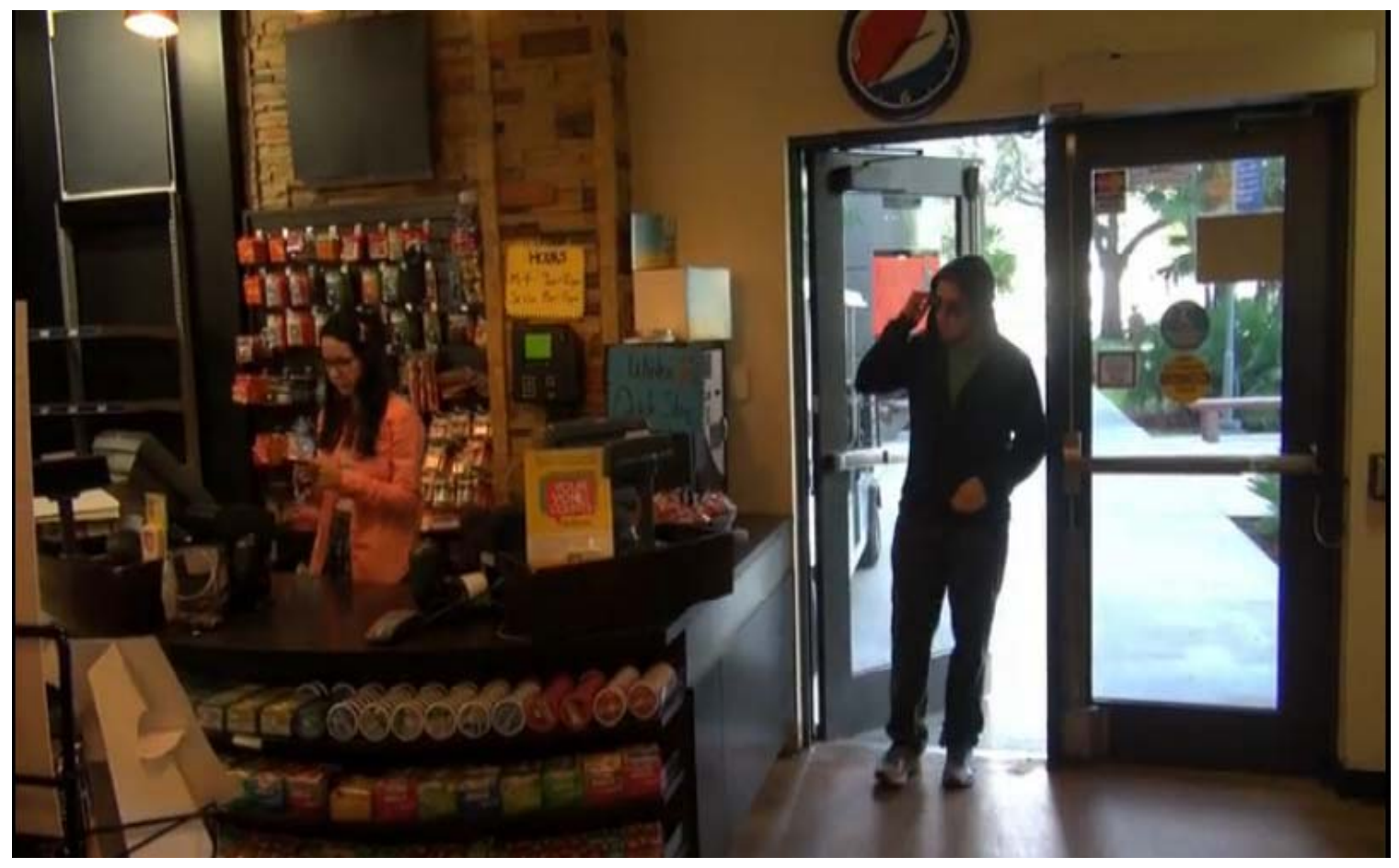


Appendix C

Number connection distractor puzzle

Please connect only the odd numbered boxes below going from highest (starting at 31) to lowest (ending at 1). Once you have finished with this page, move on to the next.

\section{9

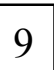

\section{3}

5
1

14

16

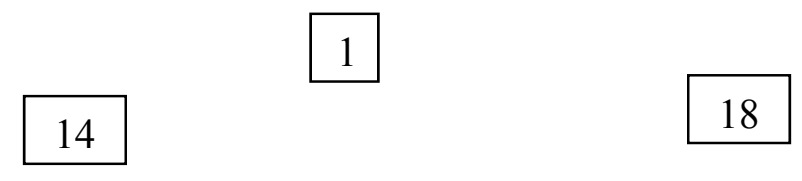

\section{6}

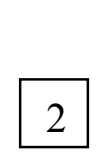

22

\section{1}

25

19

\section{4}

31

10

27

17

30

7

20

28

8

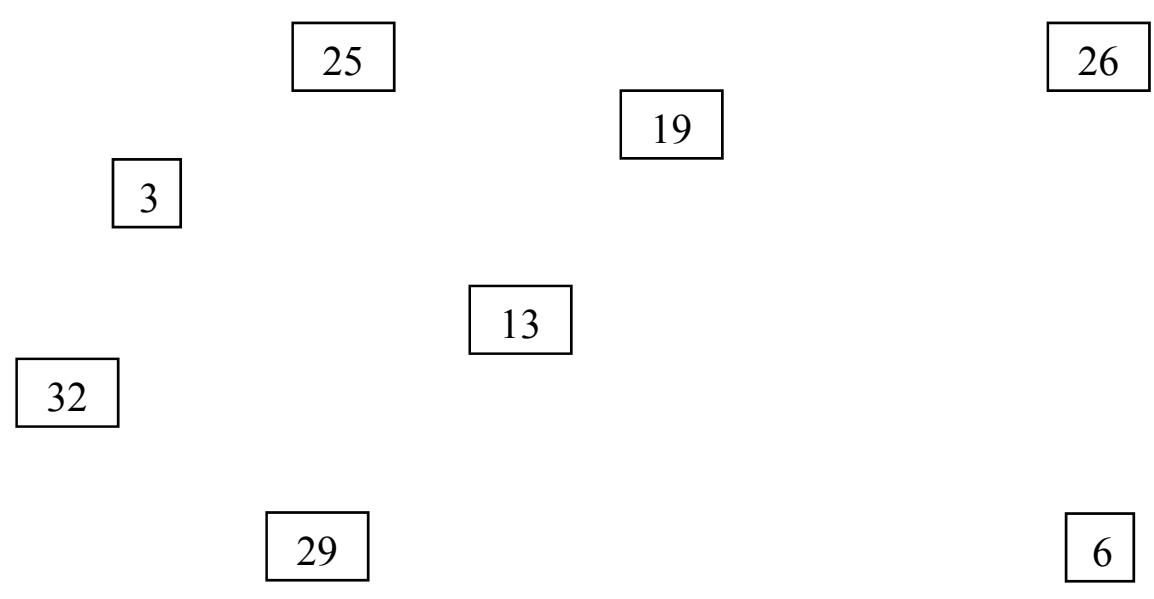




\section{Appendix D}

Open-ended question script

"I am now going to ask you some questions about what you saw on the DVD. Because I have never seen the DVD you just watched, I am required to read you the following questions."

1) "Tell me everything that you can remember about what you just witnessed."

2) "Tell me everything you can remember about the perpetrator."

3) "Tell me everything you can remember about any witnesses."

4) "Tell me everything you can remember about the location of the crime."

5) "Is there anything else you can remember?" [This question was repeated until the participant explicitly stated that he or she could not remember anything else.] 
Appendix E

Cued question script

1) INT: What color were the frames of the glasses the cashier was wearing?

2) INT: What was the race of the perpetrator?

3) INT: What did the perpetrator put in his pocket?

4) INT: What was the first thing the perpetrator touched in the store?

5) INT: What was the color of the sign displaying the store's hours?

6) INT: What was the male customer holding when the robbery began?

7) INT: What was the color of the shirt underneath the perpetrator's sweatshirt?

8) INT: What color was the male customer's shirt?

9) INT: How was the female customer's hair styled?

10) INT: What was the first thing the perpetrator asked for?

11) INT: What words were displayed above the case the perpetrator took something out of?

12) INT: What, if any, accessory was the female customer wearing?

13) INT: What hours was the store open on Saturday?

14) INT: What was the male customer wearing on his feet?

15) INT: How many lights were visible directly above the cashier's head?

16) INT: From your point of view, what door did the perpetrator use to enter the store?

17) INT: What color was the female customer's shirt?

18) INT: How many people were in the convenience store at the time of the robbery?

19) INT: Is there anything else you can remember? [This question was repeated until the participant explicitly stated that he or she could not remember anything else.] 
Appendix F

Self-reported measures questionnaire

\section{Length of View}

"What is the length of time you viewed the perpetrator in seconds?"

\section{Quality of View}

"On a scale of one to seven with one being extremely poor and seven being extremely clear, how would you rate your view of the perpetrator?"

$\begin{array}{lllllll}1 & 2 & 3 & 4 & 5 & 6 & 7\end{array}$
Extremely
poor
Extremely clear

\section{Attention}

"On a scale of one to seven with one being extremely low and seven being extremely high, how would you rate the level of attention that you paid to the perpetrator?"

12

3

4

5

6

Extremely

low
Extremely high

\section{Confidence}

"On a scale of one to seven with one being extremely not confident and seven being extremely confident, how confident are you that the information you gave me during the interview was accurate?"
1
2
3
4
5
6 7

Extremely not

Extremely confident confident 


\section{Ease of Recall}

"On a scale of one to seven with one being not at all easy and seven being extremely easy, how easy was it for you to recall the information you gave me during the interview?"

$\begin{array}{lllllll}1 & 2 & 3 & 4 & 5 & 6 & 7\end{array}$

Not at all

Extremely easy easy

\section{Perception of Accuracy}

"On a scale of one to seven with one being extremely inaccurate and seven being extremely accurate, how accurate was the information you gave me during the interview?"

$\begin{array}{lllllll}1 & 2 & 3 & 4 & 5 & 6 & 7\end{array}$

Extremely

Extremely

inaccurate

accurate 
Appendix G

Scale sheet given to participants when asked to rate confidence, quality of view of the perpetrator, ease of recall, and perception of accuracy

\section{SCALE}

$\begin{array}{lllllll}1 & 2 & 3 & 4 & 5 & 6 & 7\end{array}$




\author{
Appendix $\mathrm{H}$ \\ Suggestive question script \\ Accurate/Inaccurate Suggestive Questions \\ $1 / 2$ correct, $1 / 2$ incorrect suggestive questions (correct/incorrect)
}

"Now I'm going to ask you a series of more specific questions about the incident that I am going to read."

1. Was the gun black/silver?

2. Was the robber wearing sneakers/boots?

3. Was the robber wearing jeans/shorts?

4. Was the robber's sweatshirt black/grey?

5. Was the cashier holding a cell phone/pen?

6. Was the female customer carrying a dog/cat?

7. Did the robber hold the gun in his right/left hand?

8. Were there $2 /$ Was there 1 door in the convenience store?

9. Did the perpetrator pick up a drink/chips while in the store?

10 . Were there $3 / 2$ people in the convenience store at the time of the robbery?

11. Did the robber have any facial hair/Was the robber clean shaven?

12. Was the female customer's shirt blue/green?

13. Was the female customer wearing a purse/necklace?

14. Was the female customer's hair pulled back in a ponytail/down and behind her shoulders?

15. Was the male witness's shirt brown/black?

16. Did the male witness have any facial hair/Was the male witness clean shaven?

17. Was the convenience store called Wink's/Val's quick stop?

18. Did the robber pull the gun out from behind his back/from his front sweatshirt pocket?

19. Was the item the female customer bought green/yellow?

20. Was the shirt the robber was wearing underneath his sweatshirt green/blue? 


\section{Appendix I}

Source monitoring questionnaire

Directions: You will now be asked to answer a set of questions. If you do not know the answer to a question, please write "I don't know" on the line pertaining to the question For each answer, you will then be asked to report where you remember learning that information (the source of that information) and then rate your confidence that the information you reported is correct. After you have responded to each question, please indicate whether you saw or heard the information: (a) "from the interviewer only," (b) "from the video only," (c) "from the interviewer and video" or (d) "Don't know."

\section{What color was the gun?}

How confident are you in the accuracy of your response?

1

Not at all confident

$$
2
$$

3
4

Somewhat confident
7

Extremely confident

Where do you remember encountering this information?
a. From the interviewer only
b. From the video only
c. From the interviewer and video
d. Don't know

How confident are you that you accurately remember the source of the information?

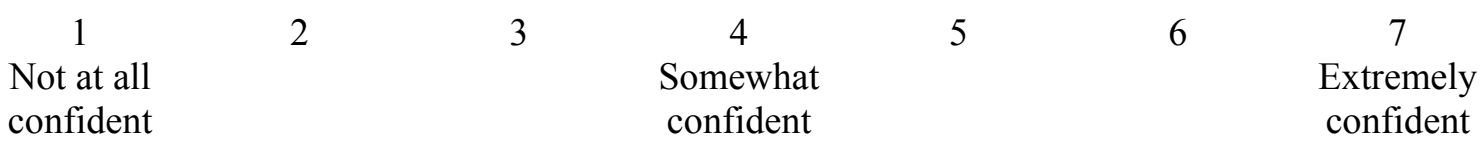

\section{What was the robber wearing on his feet?}

How confident are you in the accuracy of your response?

$\begin{array}{ccccccc}1 & 2 & 3 & 4 & 5 & 6 & 7 \\ \begin{array}{c}\text { Not at all } \\ \text { confident }\end{array} & & \begin{array}{c}\text { Somewhat } \\ \text { confident }\end{array} & & & \begin{array}{c}\text { Extremely } \\ \text { confident }\end{array}\end{array}$

Where do you remember encountering this information?
a. From the interviewer only
b. From the video only
c. From the interviewer and video
d. Don't know 
How confident are you that you accurately remember the source of the information?

$\begin{array}{ccccccc}1 & 2 & 3 & \begin{array}{c}4 \\ \text { Somewhat } \\ \text { confident }\end{array} & 5 & 6 & \begin{array}{c}7 \\ \text { Extremely } \\ \text { confident }\end{array}\end{array}$

\section{What bottoms was the robber wearing?}

How confident are you in the accuracy of your response?

$\begin{array}{ccccccc}1 & 2 & 3 & 4 & 5 & 6 & 7 \\ \begin{array}{c}\text { Not at all } \\ \text { confident }\end{array} & & \begin{array}{c}\text { Somewhat } \\ \text { confident }\end{array} & & \begin{array}{c}\text { Extremely } \\ \text { confident }\end{array}\end{array}$

Where do you remember encountering this information?
a. From the interviewer only
b. From the video only
c. From the interviewer and video
d. Don't know

How confident are you that you accurately remember the source of the information?

$\begin{array}{ccccccc}1 & 2 & 3 & 4 & 5 & 6 & 7 \\ \begin{array}{l}\text { Not at all } \\ \text { confident }\end{array} & & \begin{array}{c}\text { Somewhat } \\ \text { confident }\end{array} & & \begin{array}{c}\text { Extremely } \\ \text { confident }\end{array}\end{array}$

\section{What color was the robber's sweatshirt?}

How confident are you in the accuracy of your response?

$\begin{array}{lllllll}1 & 2 & 3 & 4 & 5 & 6 & 7\end{array}$

Not at all

confident

Where do you remember encountering this information?
a. From the interviewer only
c. From the interviewer and video
b. From the video only
d. Don't know

Extremely confident

How confident are you that you accurately remember the source of the information?

1

Not at all

confident
2

2

3

4

Somewhat confident
7

Extremely

confident 


\section{What was the cashier holding in her hand?}

How confident are you in the accuracy of your response?

$\begin{array}{ccccccc}1 & 2 & 3 & \begin{array}{c}4 \\ \text { Somewhat } \\ \text { confident }\end{array} & 5 & 6 & \begin{array}{c}7 \\ \text { Extremely } \\ \text { confident }\end{array}\end{array}$

Where do you remember encountering this information?
a. From the interviewer only
b. From the video only
c. From the interviewer and video
d. Don't know

How confident are you that you accurately remember the source of the information?

$\begin{array}{ccccccc}1 & 2 & 3 & 4 & 5 & 6 & 7 \\ \begin{array}{l}\text { Not at all } \\ \text { confident }\end{array} & & \begin{array}{c}\text { Somewhat } \\ \text { confident }\end{array} & & & \begin{array}{c}\text { Extremely } \\ \text { confident }\end{array}\end{array}$

\section{What animal was the female customer carrying?}

How confident are you in the accuracy of your response?

$\begin{array}{ccccccc}1 & 2 & 3 & \begin{array}{c}4 \\ \text { Somewhat } \\ \text { confident }\end{array} & 5 & 6 & \begin{array}{c}7 \\ \text { Extremely } \\ \text { confident }\end{array}\end{array}$

Where do you remember encountering this information?
a. From the interviewer only
b. From the video only
c. From the interviewer and video
d. Don't know

How confident are you that you accurately remember the source of the information?

$\begin{array}{ccccccc}1 & 2 & 3 & 4 & 5 & 6 & 7 \\ \begin{array}{l}\text { Not at all } \\ \text { confident }\end{array} & & \begin{array}{c}\text { Somewhat } \\ \text { confident }\end{array} & & \begin{array}{c}\text { Extremely } \\ \text { confident }\end{array}\end{array}$

\section{Which hand did the robber hold the gun in?}

How confident are you in the accuracy of your response?

$\begin{array}{ccccccc}1 & 2 & 3 & 4 & 5 & 6 & 7 \\ \text { ot at all } & & \begin{array}{c}\text { Somewhat } \\ \text { confident }\end{array} & & \begin{array}{c}\text { Extremely } \\ \text { confident }\end{array}\end{array}$


Where do you remember encountering this information?
a. From the interviewer only
c. From the interviewer and video
b. From the video only
d. Don't know

How confident are you that you accurately remember the source of the information?

$\begin{array}{ccccccc}1 & 2 & 3 & 4 & 5 & 6 & 7 \\ \begin{array}{c}\text { Not at all } \\ \text { confident }\end{array} & & \begin{array}{c}\text { Somewhat } \\ \text { confident }\end{array} & & \begin{array}{c}\text { Extremely } \\ \text { confident }\end{array}\end{array}$

\section{How many doors were there at the entrance of the convenience store?}

How confident are you in the accuracy of your response?

$\begin{array}{ccccccc}1 & 2 & 3 & \begin{array}{c}4 \\ \text { Somewhat } \\ \text { confident all }\end{array} & 5 & 6 & \begin{array}{c}7 \\ \text { Extremely } \\ \text { confident }\end{array}\end{array}$

Where do you remember encountering this information?
a. From the interviewer only
b. From the video only
c. From the interviewer and video
d. Don't know

How confident are you that you accurately remember the source of the information?

$\begin{array}{ccccccc}1 & 2 & 3 & 4 & 5 & 6 & 7 \\ \begin{array}{c}\text { Not at all } \\ \text { confident }\end{array} & & \begin{array}{c}\text { Somewhat } \\ \text { confident }\end{array} & & & \begin{array}{c}\text { Extremely } \\ \text { confident }\end{array}\end{array}$

\section{What item did the robber pick up while shopping?}

How confident are you in the accuracy of your response?

1

Not at all confident

$$
2
$$

$$
3
$$

4

Somewhat confident
7

Extremely confident

Where do you remember encountering this information?
a. From the interviewer only
b. From the video only
c. From the interviewer and video
d. Don't know 
How confident are you that you accurately remember the source of the information?

1

Not at all

confident

2

(1)

\section{3}
Somewhat confident

4
$5 \quad 6$

Extremely

confident

10. How many people were in the convenience store at the time of the robbery?

How confident are you in the accuracy of your response?

$\begin{array}{ccccccc}1 & 2 & 3 & 4 & 5 & 6 & 7 \\ \begin{array}{c}\text { Not at all } \\ \text { confident }\end{array} & & \begin{array}{c}\text { Somewhat } \\ \text { confident }\end{array} & & \begin{array}{c}\text { Extremely } \\ \text { confident }\end{array}\end{array}$

Where do you remember encountering this information?
a. From the interviewer only
b. From the video only
c. From the interviewer and video
d. Don't know

How confident are you that you accurately remember the source of the information?

$\begin{array}{ccccccc}1 & 2 & 3 & 4 & 5 & 6 & 7 \\ \begin{array}{c}\text { Not at all } \\ \text { confident }\end{array} & & \begin{array}{c}\text { Somewhat } \\ \text { confident }\end{array} & & \begin{array}{c}\text { Extremely } \\ \text { confident }\end{array}\end{array}$

\section{Did the robber have any facial hair?}

How confident are you in the accuracy of your response?

$\begin{array}{lllllll}1 & 2 & 3 & 4 & 5 & 6 & 7\end{array}$

Not at all

confident
Somewhat

confident
Extremely

confident

Where do you remember encountering this information?
a. From the interviewer only
c. From the interviewer and video
b. From the video only
d. Don't know

How confident are you that you accurately remember the source of the information?

1

Not at all

confident
2
3

3

(1)

5

Somewhat confident
7

Extremely

confident 


\section{What color was the female customer's shirt?}

How confident are you in the accuracy of your response?

$\begin{array}{ccccccc}1 & 2 & 3 & \begin{array}{c}4 \\ \text { Somewhat } \\ \text { confident }\end{array} & 5 & 6 & \begin{array}{c}7 \\ \text { Extremely } \\ \text { confident }\end{array}\end{array}$

Where do you remember encountering this information?
a. From the interviewer
b. From the video
c. From the interviewer and video
d. Don't know

How confident are you that you accurately remember the source of the information?

$\begin{array}{ccccccc}1 & 2 & 3 & 4 & 5 & 6 & 7 \\ \begin{array}{l}\text { Not at all } \\ \text { confident }\end{array} & & \begin{array}{c}\text { Somewhat } \\ \text { confident }\end{array} & & \begin{array}{c}\text { Extremely } \\ \text { confident }\end{array}\end{array}$

13. What if any accessory was the female customer wearing?

How confident are you in the accuracy of your response?

$\begin{array}{ccccccc}1 & 2 & 3 & \begin{array}{c}4 \\ \text { Somewhat } \\ \text { cot at all }\end{array} & 5 & 6 & \begin{array}{c}7 \\ \text { Extremely } \\ \text { confident }\end{array}\end{array}$

Where do you remember encountering this information?
a. From the interviewer only
c. From the interviewer and video
b. From the video only
d. Don't know

How confident are you that you accurately remember the source of the information?

1

Not at all confident

$$
2
$$

3

3

4

Somewhat confident
7

Extremely confident

\section{How was the female customer's hair styled?}

How confident are you in the accuracy of your response?

1

Not at all confident

2

3
4

Somewhat confident
7

Extremely confident 
Where do you remember encountering this information?
a. From the interviewer only
b. From the video only
c. From the interviewer and video
d. Don't know

How confident are you that you accurately remember the source of the information?

$\begin{array}{ccccccc}1 & 2 & 3 & 4 & 5 & 6 & 7 \\ \begin{array}{c}\text { Not at all } \\ \text { confident }\end{array} & & \begin{array}{c}\text { Somewhat } \\ \text { confident }\end{array} & & \begin{array}{c}\text { Extremely } \\ \text { confident }\end{array}\end{array}$

\section{What color was the male witness's shirt?}

How confident are you in the accuracy of your response?

$\begin{array}{ccccccc}1 & 2 & 3 & 4 & 5 & 6 & 7 \\ \begin{array}{c}\text { Not at all } \\ \text { confident }\end{array} & & \begin{array}{c}\text { Somewhat } \\ \text { confident }\end{array} & & \begin{array}{c}\text { Extremely } \\ \text { confident }\end{array}\end{array}$

Where do you remember encountering this information?
a. From the interviewer only
b. From the video only
c. From the interviewer and video
d. Don't know

How confident are you that you accurately remember the source of the information?

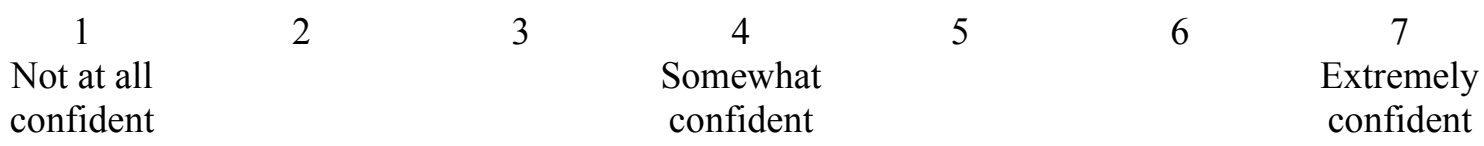

\section{Did the male witness have any facial hair?}

How confident are you in the accuracy of your response?

$\begin{array}{ccccccc}1 & 2 & 3 & 4 & 5 & 6 & 7 \\ \begin{array}{c}\text { Not at all } \\ \text { confident }\end{array} & & \begin{array}{c}\text { Somewhat } \\ \text { confident }\end{array} & & \begin{array}{c}\text { Extremely } \\ \text { confident }\end{array}\end{array}$

Where do you remember encountering this information?
a. From the interviewer only
b. From the video only
c. From the interviewer and video
d. Don't know

How confident are you that you accurately remember the source of the information?

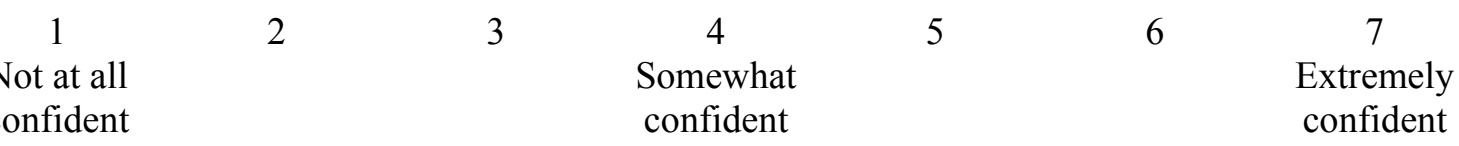




\section{What was the name of the convenience store?}

How confident are you in the accuracy of your response?

$\begin{array}{ccccccc}1 & 2 & 3 & \begin{array}{c}4 \\ \text { Somewhat } \\ \text { confident }\end{array} & 5 & 6 & \begin{array}{c}7 \\ \text { Extremely } \\ \text { confident }\end{array}\end{array}$

Where do you remember encountering this information?
a. From the interviewer only
b. From the video only
c. From the interviewer and video
d. Don't know

How confident are you that you accurately remember the source of the information?

$\begin{array}{ccccccc}1 & 2 & 3 & 4 & 5 & 6 & 7 \\ \begin{array}{l}\text { Not at all } \\ \text { confident }\end{array} & & \begin{array}{c}\text { Somewhat } \\ \text { confident }\end{array} & & & \begin{array}{c}\text { Extremely } \\ \text { confident }\end{array}\end{array}$

\section{Where did the robber keep the gun?}

How confident are you in the accuracy of your response?

$\begin{array}{ccccccc}1 & 2 & 3 & \begin{array}{c}4 \\ \text { Somewhat } \\ \text { confident all }\end{array} & 5 & 6 & \begin{array}{c}7 \\ \text { Extremely } \\ \text { confident }\end{array}\end{array}$

Where do you remember encountering this information?
a. From the interviewer only
c. From the interviewer and video
b. From the video only
d. Don't know

How confident are you that you accurately remember the source of the information?

1

Not at all confident
2

3

3

4

Somewhat confident
7

Extremely

confident

19. What color was the item that the female customer purchased? 
How confident are you in the accuracy of your response?

$\begin{array}{ccccccc}1 & 2 & 3 & \begin{array}{c}4 \\ \text { Somewhat } \\ \text { confident }\end{array} & 5 & 6 & \begin{array}{c}7 \\ \text { Extremely } \\ \text { confident }\end{array}\end{array}$

Where do you remember encountering this information?
a. From the interviewer only
b. From the video only
c. From the interviewer and video
d. Don't know

How confident are you that you correctly remember this information?

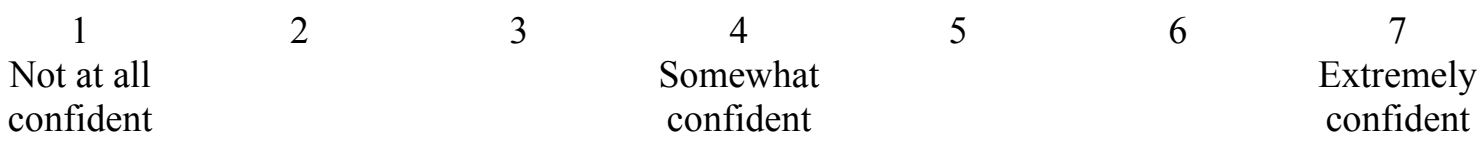

\section{What color was the robber's shirt that he wore underneath his sweatshirt?}

How confident are you in the accuracy of your response?

$\begin{array}{ccccccc}1 & 2 & 3 & 4 & 5 & 6 & 7 \\ \begin{array}{c}\text { Not at all } \\ \text { confident }\end{array} & & \begin{array}{c}\text { Somewhat } \\ \text { confident }\end{array} & & \begin{array}{c}\text { Extremely } \\ \text { confident }\end{array}\end{array}$

Where do you remember encountering this information?
a. From the interviewer only
b. From the video only
c. From the interviewer and video
d. Don't know

How confident are you that you correctly remember this information?

1

Not at all confident

\section{3}

4

Somewhat confident
7

Extremely confident 
Appendix $\mathbf{J}$

Rapport questionnaire

Directions: Rate the experimenter (who interviewed you today) on the following characteristics

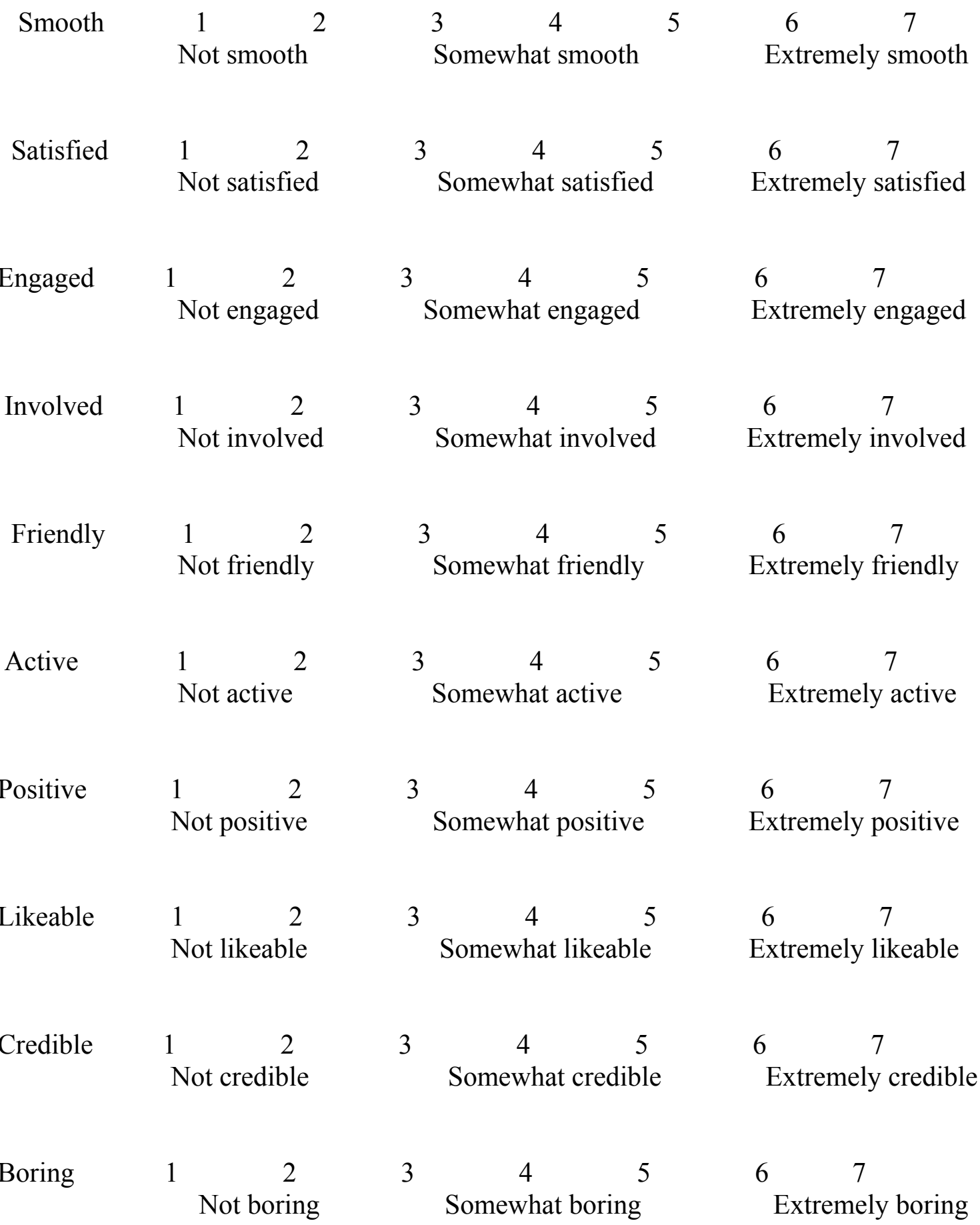




\begin{tabular}{|c|c|c|c|c|c|}
\hline Cooperative & 1 & $\begin{array}{c}2 \\
\text { Not cooperative }\end{array}$ & 3 & $\begin{array}{cc}4 & 5 \\
\text { Somewhat cooperative }\end{array}$ & $\begin{array}{c}6 \\
\text { Extremely cooperative }\end{array}$ \\
\hline Harmonious & 1 & $\begin{array}{c}2 \\
\text { Not harmonious }\end{array}$ & 3 & $\begin{array}{cc}4 & 5 \\
\text { Somewhat harmonious }\end{array}$ & $\begin{array}{cc}6 & 7 \\
\text { Extremely harmonious }\end{array}$ \\
\hline Unsatisfying & 1 & $\begin{array}{c}2 \\
\text { Unsatisfying }\end{array}$ & 3 & $\begin{array}{l}4 \\
\text { Satisfying }\end{array}$ & $\begin{array}{l}6 \\
\text { Extremely satisfying }\end{array}$ \\
\hline Cold & 1 & $\begin{array}{c}2 \\
\text { Not cold }\end{array}$ & 3 & $\begin{array}{cc}4 & 5 \\
\text { Somewhat cold }\end{array}$ & $\begin{array}{c}7 \\
\text { Extremely cold }\end{array}$ \\
\hline Awkward & 1 & $\begin{array}{c}2 \\
\text { Not awkward }\end{array}$ & 3 & $\begin{array}{cc}4 & 5 \\
\text { Somewhat awkward }\end{array}$ & $\begin{array}{lc}6 & 7 \\
& \text { Extremely awkward }\end{array}$ \\
\hline Engaging & 1 & $\begin{array}{c}2 \\
\text { Not engaging }\end{array}$ & 3 & $\begin{array}{cc}4 & 5 \\
\text { Somewhat engaging }\end{array}$ & $\begin{array}{lc}6 & 7 \\
& \text { Extremely engaging }\end{array}$ \\
\hline Unfocused & 1 & $\begin{array}{c}2 \\
\text { Not focused }\end{array}$ & 3 & $\begin{array}{lr}4 & 5 \\
& \text { Focused }\end{array}$ & $\begin{array}{lc}6 & 7 \\
& \text { Extremely focused }\end{array}$ \\
\hline Involving & 1 & $\begin{array}{c}2 \\
\text { Not involving }\end{array}$ & 3 & $\begin{array}{cc}4 & 5 \\
\text { Somewhat involving }\end{array}$ & $\begin{array}{l}6 \\
\text { Extremely involving }\end{array}$ \\
\hline
\end{tabular}




\section{Appendix K}

Cognitive load questionnaire

1. When interviewed about the crime today, how much did you think about if the interviewer was evaluating you?
1
2
3
4
5
6

Not at all

A lot

2. When interviewed about the crime today, how thoroughly were you able to search through your memory?
1
2
3
4
5
6
7

Not at all

Very thoroughly

3. When interviewed about the crime today, how much were you thinking about other things besides the crime?
1
2
3
4
5
6
7

Not at all

A lot

4. If you were thinking/focusing on other things while you were remembering the crime, please describe those.

5. When remembering the crime today, how much mental effort did you use/spend on providing accurate and plentiful information?
1
2
3
4
5
6
7

Very low

Very high

mental effort mental effort

6. When remembering the crime today, how difficult was it to thoroughly search your memory?
1
2
3
4
5
6
7

Not at all

Extremely

difficult

difficult 


\section{Appendix L \\ Participant suspicion questionnaire}

1. What do you believe was the purpose of this study?

2. Do you believe the experimenter saw the video prior to this study? Please circle one.

Yes $\quad$ No

3. Do you believe deception was involved in this study?

Yes $\quad$ No

3a. If you answered "yes" please explain.

4. Did you believe the experimenter when he/she said that the first video did not record?

Yes No

4a. Why or why not? 


\section{Appendix M}

Procedure

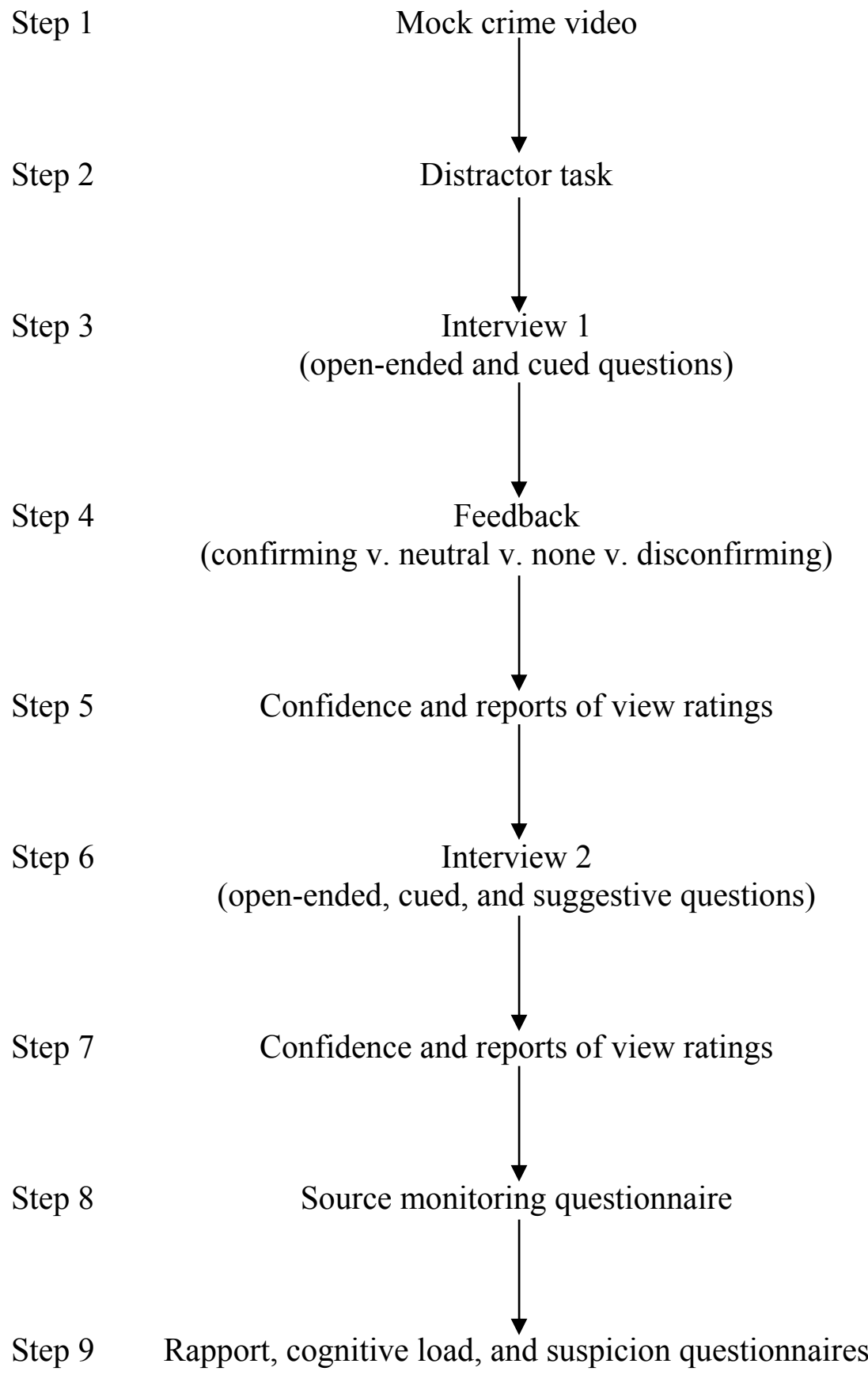


VITA

\section{DANA HIRN MUELLER}

Born: Sturgeon Bay, Wisconsin

B.A. Psychology, University of Wisconsin - Milwaukee 2008

B.S. Criminal Justice, University of Wisconsin - Milwaukee 2010

M.S. Legal Psychology, Florida International University, Miami, FL 2014 Thesis title: Examining memory for decisions and memory for external events using delayed and repeated recall Thesis Advisor: Ronald P. Fisher, Ph.D.

\section{PUBLICATIONS AND PRESENTATIONS}

Hirn Mueller, D., Schreiber Compo, D., Molina, J., Bryon, A., \& Pimentel, P. (in press). Productive and counter-productive interviewing techniques: Do law enforcement interviewers know the difference? Psychology, Public Policy, and Law.

Hirn Mueller, D., \& Schreiber Compo, N. (2015). Missed opportunities for justice. In S. Schwartz (Ed.). Where Psychology and Law Intersect: Issues in Legal Psychology, (pp.250-281). San Diego, CA: Cognella Academic Publishing.

Rivard, J., Fisher, R. P., Robertson, B., Hirn Mueller, D. (in press). Testing the cognitive interview with professional interviewers: Enhancing recall of specific details of recurring events. Applied Cognitive Psychology.

Fisher, R. P., Schreiber Compo, N., Rivard, J., \& Hirn, D. (in press). Interviewing witnesses. Handbook of Applied Memory. In T. Perfect and S. Lindsay (Eds.).

Hirn Muller, D. (July, 2014). The importance of witness recall in avoiding wrongful convictions. American Psychology-Law Society Newsletter, 14-20.

Hirn Mueller, D., Schreiber Compo, N., Valdes, A., Estrada, J., \& Padron, K. (2015, March). Examining the impact of post-recall feedback on subsequent witness recall and confidence. Paper presented at the annual meeting of the American Psychology-Law Society, San Diego, CA.

Hirn Mueller, D., \& Schreiber Compo, N. (2015, March). Exploring the relationship between law enforcement training and perceptions of investigative interviewing techniques. Poster presented at the annual meeting of the American Psychology-Law Society, San Diego, CA. 
Hirn Mueller, D., \& Schreiber Compo, N. (2015, March). The impact of post-recall feedback on witness suggestibility. Paper presented at the annual meeting of the Academy of Criminal Justice Sciences, Orlando, FL.

Hirn Mueller, D., \& Schreiber Compo, N. (2014, May). Examining the impact of postrecall feedback on witness confidence, recall, and perception. Paper presented at the meeting of the UM/FIU Southeast Cross University Collaborative Mentoring Conference, Miami, FL.

Hirn Mueller, D., \& Charman, S. (2014, April). Law enforcement reported use of best practice lineup techniques. Paper presented at the meeting of the Florida International University Graduate Symposium, Miami, FL.

Fisher, R. P., Hirn Mueller, D., \& Robertson, B. (2014, March). Using the Cognitive Interview to elicit information about organizations. Paper presented at the annual meeting of the American Psychology-Law Society, New Orleans, LA.

Charman, S., Hirn Mueller, D., \& Kavetski, M. (2014, March). Investigator decision making: Evidence evaluation among police officers across the United States. Paper presented at the annual meeting of the American Psychology-Law Society, New Orleans, LA.

Hirn Mueller, D., Schreiber Compo, N., Pimentel, P., Molina, J., \& Bryon, A. (2014, March). Best practice and problematic investigative interviewing techniques: Do police interviewers know the difference? Paper presented at the annual meeting of the American Psychology-Law Society, New Orleans, LA.

Hirn Mueller, D., Schreiber Compo, N., Pimentel, P., Molina, J., \& Bryon, A. (2014, February). Law enforcement perception and reported use of best practice and problematic interviewing techniques. Paper presented at the annual meeting of the Academy of Criminal Justice Sciences, Philadelphia, PA.

Hirn, D. E., Schreiber Compo, N., \& Pimentel, P. (2013, March). Law enforcement knowledge of research-based interviewing techniques. Paper presented at the meeting of the Florida International University Graduate Symposium, Miami, FL.

Hirn, D. E., Fisher, R. P., \& Carol, R. (2012, May). Use of a hybrid interview method to retrieve memories created during decision making: Examining delays. Paper presented at the meeting of the International Investigative Interviewing Research Group, Toronto, Ontario.

Hirn, D. E., Fisher, R. P., \& Carol, R. (2012, March). Use of a hybrid interview method to retrieve memories created during decision making. Paper presented at the meeting of the American Psychology-Law Society, San Juan, PR. 